This item was submitted to Loughborough's Research Repository by the author.

Items in Figshare are protected by copyright, with all rights reserved, unless otherwise indicated.

\title{
Artificial intelligence and food security: swarm intelligence of AgriTech drones for smart AgriFood operations
}

PLEASE CITE THE PUBLISHED VERSION

https://doi.org/10.1080/09537287.2021.1882688

PUBLISHER

Taylor \& Francis

VERSION

AM (Accepted Manuscript)

PUBLISHER STATEMENT

This is an Accepted Manuscript of an article published by Taylor \& Francis in Production Planning \& Control on 25 Feb 2021, available online: https://doi.org/10.1080/09537287.2021.1882688.

\section{LICENCE}

CC BY-NC-ND 4.0

\section{REPOSITORY RECORD}

Spanaki, Konstantina, Erisa Karafili, Uthayasankar Sivarajah, Stella Despoudi, and Zahir Irani. 2021. "Artificial Intelligence and Food Security: Swarm Intelligence of Agritech Drones for Smart Agrifood Operations". Loughborough University. https://hdl.handle.net/2134/12671660.v1. 


\title{
Artificial Intelligence and Food Security: Swarm Intelligence of AgriTech Drones for Smart AgriFood Operations
}

\author{
Konstantina Spanaki ${ }^{a^{*}}$, Erisa Karafili ${ }^{\mathrm{b}}$, Uthayasankar Sivarajah ${ }^{\mathrm{c}}$, Stella \\ Despoudi ${ }^{\mathrm{d}}$, Zahir Irani ${ }^{\mathrm{c}}$
}

${ }^{\text {a }}$ School of Business and Economics, Loughborough University, Loughborough Leicestershire LE11 3TU United Kingdom

${ }^{\mathrm{b}}$ School of Electronics and Computer Science, University of Southampton, Southampton SO17 1BJZ, United Kingdom

${ }^{\mathrm{c}}$ School of Management, University of Bradford, Bradford, BD9 4JL, United Kingdom

${ }^{\mathrm{d}}$ Aston Business School, Aston University, Birmingham, B4 7ET, United Kingdom

*Corresponding email address: K.Spanaki@lboro.ac.uk

\section{Acknowledgements:}

Erisa Karafili was supported by the European Union's H2020 research and innovation programme under the Marie Skłodowska-Curie grant (agreement No. 746667). 


\title{
Artificial Intelligence and Food Security: Swarm Intelligence of AgriTech Drones for Smart AgriFood Operations
}

\begin{abstract}
The Sustainable Development Goals (SDGs) present the emerging need to explore new ways of AgriFood production and food security as ultimate targets for feeding future generations. The study adopts a Design Science methodology and proposes Artificial Intelligence (AI) techniques as a solution to food security problems. Specifically, the proposed artefact presents the collective use of Agricultural Technology (AgriTech) drones inspired by the biomimetic ways of bird swarms. The design (artefact) appears here as a solution for supporting farming operations in inaccessible land, so as unmanned aerial devices contribute and improve the productivity of farming areas with limited capacity. The proposed design is developed through a scenario of drone swarms applying AI techniques to address food security issues. The study concludes by presenting a research agenda and the sectoral challenges triggered by the applications of AI in Agriculture.
\end{abstract}

Keywords: AgriFood Sector, Artificial Intelligence (AI), Swarm Intelligence (SI), Sustainable Development Goals (SDGs), Food Security

\section{Introduction}

Over the last decades, the AgriFood sector has been facing many challenges concerning population growth, limited farming land, scarcity of natural resources, and climatic changes (FAO, 2018). The primary natural resources, which include food, energy and water are constantly becoming scarce (FAO, 2018; 2011). The future scarcity of the natural resources indicates that they need to be preserved, and they should not intentionally be wasted. Evidence has shown that arable land is limited; therefore, new ways of growing crops need to be developed in places that until now was not possible to farm (Vidal, 2012). By 2050 the world population has been predicted to reach nine billion, and this calls for food security which means about $70 \%$ increase in food production (FAO, 2018), and also reduction of food waste and loss which is currently almost $30 \%$ of the output (Irani et al. 2018). Producing enough food, appropriately distributing it, and minimising its wastage are some of the critical challenges that the AgriFood industry is facing related to the rising population (Schanes, Dobernig, and Gözet 
2018; Papargyropoulou et al. 2014; Irani and Sharif 2018) and those challenges indicate the urgency for agriculture to become more sustainable.

Agricultural Technology (AgriTech) applies Artificial Intelligence (AI), and data-driven approaches to provide increased efficiency and solutions to various AgriFood problems (Kittipanya-ngam and Tan 2020). The sustainability and food security goals as they also appear in the SDGs agenda, require radical and innovative solutions based on alternative ways of AgriFood production, therefore the SDGs support data-driven and AI-related approaches (Sony and Naik 2019). AgriFood supply chains and operations, in particular, show specific challenges due to their unique nature different from global supply chains and their distinguishing characteristics (Moazzam et al. 2018). Also, that is the reason, why relevant solutions should be targeted to specific problems for AgriFood supply chains. AgriFood challenges can be vast and variable (Vlajic, Mijailovic, and Bogdanova 2018) such as perishability of the production, production seasonality, variability in quality and quantity, long production throughput time and specialised transportation requirements (Moazzam et al. 2018) and also associated variable risks (Wang, Li, and Shi 2012). The SDGs highlight specific goals for "Food Security" in order to show the importance and the unique requirements and tailored solutions required for AgriFood production problems.

The study explores solutions through the applications of AI in the AgriFood sector, and towards this end, an exploratory Design Science Research (DSR) methodology is driving the solutionbased approach. The DSR method is applied to enhance and develop an artefact of AI techniques, and provide a solution to the problem of dispersing arable land remaining idle and hindering the AgriFood production. Against this backdrop, the critical problem and our main research question that should be presented here: How can Artificial Intelligence (AI) be adapted for enhancing the AgriFood production and facilitating the farming operations of inaccessible arable land remotely? Therefore, this study aims to explore through problem-oriented DSR the applications of AI associated with AgriFood production and identify new ways that could improve food security and provide indicative solutions for the problem of inaccessible arable land.

The paper unfolds as follows: it starts with an initial exploration of the relevant, sustainable development goals (SDGs) for food security and the context of sustainability in AgriFood sector, then the discussion moves to new ways of food production through the applications of artificial intelligence in the farming sector (in the form of Agricultural Technology). 
Additionally, it presents the methodological approach through a Design Science Research (DSR) paradigm and extends the DSR approach on the ways AI could be applied for the food security goal (swarm intelligence of drones for this instance). The DSR approach builds a solution-driven artefact based on the background of AI and collective intelligence of swarms (swarm intelligence). The application of the artefact is presented through a scenario of AgriFood operations enhanced with the application of drones monitoring the production of remote arable land. Swarm Intelligence (SI) proposed in the scenario is following a problemoriented trigger and inspiration from the biomimetic way of bird swarms and can enhance practices for the farming operations. Finally, the paper provides a further discussion and analysis of the SDGs, where the proposed swarm intelligence techniques could be applied.

\section{Sustainable Development Goals (SDGs) for Food Security and AgriFood Operations}

Although there are varying interpretations of the term sustainability in the extant literature, the study herein conceives sustainability in terms of the compromises of the developments and the required changes, but also the interventions incorporated in order to decrease environmental effects and improve socio-economic conditions (Sivarajah et al., 2019; Ahmadi et al., 2017). The United Nations introduced the Sustainable Development Goals (SDGs) in 2016 whereby a set of worldwide objectives designed to end poverty, protect the planet and guarantee that all individuals have peace and prosperity by 2030 (Sachs, 2012). The UN replaced the eight Millennium Development Goals from 2000 with the 17 SDGs which were integrated and indivisible across the three pillars of sustainability; economic growth, social inclusion and environmental protection (Halisçelik and Soytas, 2019 p.2; Sachs, 2012). All the SDG objectives are interrelated, and the way to progress is often identified with issues that are even more firmly related to each another (Ashraf et al., 2019). While setting the scope of our research within the "food security" agenda of the SDGs, the proposed approach could also be applied for aspects of the AgriFood sector relevant to other SDG goals as zero hunger (goal 2), responsible consumption and production (goal 12), life below water (goal 14) and life on land (goal 15).

The SDGs relevant to the AgriFood sector is depicted in Table 1, and these are zero hunger (goal 2), responsible consumption and production (goal 12), life below water (goal 14) and life on land (goal 15). The majority of extant scholarly studies focusing on food security within the AgriFood sector still cannot provide clear linkages and relate how the research could progress 
any of the relevant related SDGs. Rendering the SDGs into specific actions is vital for the various stakeholders involved in the AgriFood Sector (researchers, industry practitioners, policymakers and consumers) as this can have a direct impact on preserving the sustainability of the AgriFood systems and adversely tackling significant societal challenges.

Table 1: UN SDGs Food Security Goals

\begin{tabular}{|c|c|}
\hline $\begin{array}{l}\text { SDG } \\
\text { Goal }\end{array}$ & Themes and Research Areas related to Food Security \\
\hline \multirow{4}{*}{$\begin{array}{l}0 \\
\stackrel{0}{0} \\
N \\
1 \\
N \\
0 \\
0 \\
0\end{array}$} & - Increasing sustainable food production and lower food prices \\
\hline & - Investment in rural agricultural infrastructure \\
\hline & - Implement resilient and sustainable agriculture practices \\
\hline & - Reduced food imports \\
\hline \multirow{6}{*}{ 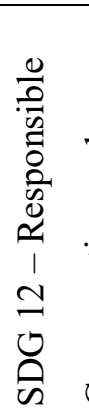 } & - Reduction of food waste and food losses \\
\hline & - Encourage agribusiness innovation \\
\hline & - Encourage agri-business sustainability reporting \\
\hline & - Increase agricultural land productivity \\
\hline & - Better management of agricultural fertilisers and waste \\
\hline & - Reduced crop and dietary diversity \\
\hline \multirow{2}{*}{ 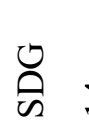 } & - Reduction of marine pollution such as ocean plastic waste \\
\hline & - Protecting marine and coastal ecosystems \\
\hline \multirow{2}{*}{ 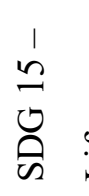 } & - Conserving and restoring natural ecosystems \\
\hline & $\begin{array}{l}\text { - } \text { Restore eroded land and soil ( inclusive of land affected by } \\
\text { desertification, drought and floods) }\end{array}$ \\
\hline
\end{tabular}

As shown in Table 1 above, the four SDGs pertinent to agriculture, target the elimination of hunger, responsible consumption and sustainability of the life on land and below water. The aforementioned SDGs in agriculture provide an agenda for alternative solutions, so as problems of the existing conventional farm management cycle can be eliminated. The AgriFood sector could follow the recent examples of data-intensive intelligent practices as these are applied in other service and production fields (i.e. manufacturing, retail, transportation ) and the associated digital transformations where the disruption of the operating models is evident in multiple industrial sectors (F. Li et al. 2016). 


\section{Research Background}

Initially, the AgriFood Sector and the challenges of sustainability and food security will be presented through the exploration of the extant literature, the Sustainable Development Goals (SDGs) and the links with Smart AgriFood practices. The following theoretical stream will explain the background of Smart Operations and the Agricultural Technology (AgriTech) and the associated shifts in the farming operating models, where the role of Artificial Intelligence (AI) is highlighted. AgriTech and AI applications are discussed further in order to move to the Swarm Intelligence artefact presented in this study.

\subsection{The AgriFood Sector and Sustainability Challenges}

The particulars of AgriFood Sector appearing in previous studies will be presented here as well as the sectoral challenges of sustainability and food security. There will also be a review of the relevant Sustainable Development Goals (SDGs) and the links with Smart AgriFood practices in order to provide a full background of the study.

AgriFood Supply Chain (ASC) can be defined as the set of activities from production to consumption that brings agricultural and/or horticultural products from the farm to the table (Aramyan et al. 2007). The most common ASC entities are the producers, wholesalers, distributors, processors, agricultural cooperatives, and retailers. Two different types of ASC exist, which are: the ASC of the fresh agricultural products and the ASC of the non-perishable agricultural products (Defra 2020). The ASC of the fresh agricultural products is characterised by-products which are highly perishable and with limited shelf-life such as fruits and vegetables (Despoudi et al. 2018; Papaioannou et al. 2020). While the ASC of horticultural products has products which are non-perishable and can be stored for long periods such as potatoes and nuts. ASCs are unique compared to other supply chains as most of their products are characterised by limited shelf-life, price variability, high-quality specifications, and dependency on weather conditions (UN Food and Agriculture Organization 2009; Moazzam et al. 2018). These unique characteristics make the ASC complex to manage.

The current ASC system has been criticised for being unsustainable (FAO 2019; Dora 2019; Despoudi 2019). The unsustainability appears as it faces many pressures related to the limited agricultural land available for farming, fewer and in some cases extinct natural resources, population growth, climatic change, and high food waste levels (Defra 2020; Govindan 2018). 
The ASC sector is also facing challenges concerning the need for improved product safety, efficient risk management and quick response capability (Wang, Li, and Shi 2012). FAO (2014) defines a sustainable ASC as a reliable, resilient and transparent supply chain, which produces food within ecological limits, empowers food producers, and ensures accessible and nutritious food for all. While, food security can be defined as a situation that exists when all people at all times have physical, social and economic access to sufficient, safe and nutritious food that meets their dietary needs and food preferences for an active healthy life (FAO 2014). An ASC that is not sustainable in the long run it cannot achieve food security (Krejci and Beamon 2014).

The existing farming methods of conventional agriculture are using mass production systems which have several social and environmental implications for individuals and societies (Wolfert et al. 2017). Natural resources such as energy and water are becoming scarce (UN Food and Agriculture Organization 2011). Preserving natural resources by using them as efficiently as possible can help to increase food security. The agricultural land, which is suitable for farming, is decreasing, and new ways to farm crops, need to be identified (CEMA - European Agricultural Machinery 2017). The climatic change also brings changes to crops, farming periods, and severe damages to crops due to extreme weather changes, the rise of global temperature, and increase of greenhouse gas emissions (Iakovou et al. 2014). The increasing world population and the expected high demand for food requires approximately a tripled production rate by 2050 (UN Food and Agriculture Organization 2009). Increasing food production will improve food availability but utilising effectively the currently produced food without wasting it is equally important. In the ASC between $25 \%$ and $50 \%$ of food produced is lost or wasted and does not reach consumers (Lundqvist, Fraiture, and Molden 2008).

Achieving a reduction in the food that is lost or wasted can increase grain supply, food availability and food security without wasting other resources such as land, labour, water and inputs (Despoudi 2020). In particular, farmers are having high percentages of food losses and waste and this impacts their livelihood and their business sustainability (Lehmann, Reiche, and Schiefer 2012). Thus, considering all the challenges mentioned above of the ASC, development of a sustainable and food secure ASC innovative solutions is deemed as necessary (CEMA European Agricultural Machinery 2017; Lezoche et al. 2020; Irani and Sharif 2018; Irani and Sharif 2016). Different innovative solutions have been suggested for far. For example, Vlajic et al. (2018) examined the reverse flows and the value recovery processes in fresh food supply chains and suggested that there are financial constraints in that. While, Kittipanya-ngam et al., (2020) suggested that the digitalisation efforts of food supply chains are challenging and quite 
resource-intensive as products may travel within the supply chain for a long period. Indicating that further research is needed to identify innovative solutions in response to the challenges of the ASC.

\subsection{Biomimicry and Artificial Intelligence (AI) applications for Sustainable AgriFood production}

The last decade the digital disruption termed as the fourth industrial revolution (Industry 4.0) has appeared in various industrial fields (Liao et al. 2017; Oesterreich and Teuteberg 2016). Farming also inevitably followed the transition from conventional practices to digitalised ways of achieving the best operational results. The focus of the new farming operations is the farmer as the core of the processes; thus the agricultural platforms collect data in order to provide planting advice, tailored recommendations and a general sense-making process of the data stemming from the fields. The Human Intelligence and logic of the farmers assisted by AI and computational logic could assist in the operational disruption of the farming sector as a whole.

Designing innovative solutions for AgriFood problems could be supported by biomimicry, a mimetic way of the way natural ecosystems behave (Kennedy et al. 2015; Pathak 2019). There are multiple examples of how nature can improve the conditions of the land, where fields in disperse areas could flourish and provide AgriFood produce naturally with the help of insects and birds. Designing the future systems in a biomimetic way, as Margolin $(1998 ; 2007)$ argues, is an elegant merger of sustainability and innovation and can allow the human civilisation to flourish within the ecological limits of the planetary support system using a sustainable template. Swarm Intelligence (SI) or even Collective Intelligence (as it is alternatively termed) is an evolving concept of AI introducing techniques typically inspired by natural phenomena, exhibiting remarkable capabilities in solving problems that are often perceived to be challenging to conventional computational techniques (X. Li and Clerc 2019). SI systems are based on self-organising behaviours lacking continuous centralised control, the facilitated interactions among entities of the swarm are usually based on logical, simple rules and decisions (Cullen et al. 2018; X. Li and Clerc 2019). The biomimetic template of enhancing the AgriFood production and operations remotely (as birds used to do) through swarms of drones is the potential solution developed and presented in this study. Building on the background of Sustainable AgriFood operations, the evolution of smart farms and AI concepts and techniques; this paper proposes swarm intelligence as a potential application of AI that could support and enhance AgriFood practices to address food security. 
At this point, it is required to define how $\mathrm{AI}$ is perceived in this study in order to move forward to the specific techniques proposed for AgriFood operations. One of the possible definitions of Artificial Intelligence (AI) refers to cognitive processes and especially to reasoning (Pomerol 1997, 3). AI applies human problem-solving behaviour and skills in complex real-world tasks, especially for knowledge processing and representation (Bielli and Reverberi 1996; Duan, Edwards, and Dwivedi 2019; Dwivedi et al. 2019). Artificial Intelligence or AI, as it is often referred, is an umbrella term to describe the use of digital technologies to perform activities, tasks and decisions normally performed by human intelligence (Pomerol 1997; Bawack, Wamba, and Carillo 2019). AI can provide the ground of multiple applications for the agrarian operations, which are within the scope of Agriculture Technology (AgriTech).

Applications of AI and machine learning in farming operations can provide valuable knowledge in order to interpret and understand better the conditions in the farming land. AgriTech supports farmers with instant and continuous insights about their yields and the crops and how they can boost their production rates (Pham and Stack 2018; Kaloxylos et al. 2012). A combination of $\mathrm{AI}$ and Human Intelligence can determine the way each farm could improve the conditions and dynamically change them accordingly so as sustainability is achieved (Yahya 2018). Sustainability for each farm through the applications of AgriTech can be perceived as achieving optimal rates of production, precise allocation of resources (water and fertilisers), and proactive action in terms of crop diseases (Fountas et al. 2015). The everyday farm operations can significantly change due to the technological advances, while the implications of AgriTech in the farming operations could be vast and promising for the AgriFood Sector but also AgriFood sustainability (Table 2).

Table 2: Applications and implications of AI in the AgriFood sector.

\begin{tabular}{|c|c|c|}
\hline $\begin{array}{c}\text { AI and } \\
\text { AgriTech } \\
\text { Applications }\end{array}$ & $\begin{array}{l}\text { Implications in the AgriFood Sector and UN } \\
\text { SDGs }\end{array}$ & References \\
\hline $\begin{array}{l}\text { IoT sensors in } \\
\text { fields }\end{array}$ & $\begin{array}{l}\text { To provide variables such as acidity, } \\
\text { nutrients, moisture, humidity and } \\
\text { temperature of the soil. } \\
\text { - To access climate forecasts to predict } \\
\text { weather patterns in the coming days and } \\
\text { weeks. }\end{array}$ & $\begin{array}{l}\text { (Nukala et al. 2016; } \\
\text { Brewster et al. 2017; } \\
\text { Popović et al. 2017; } \\
\text { Tzounis et al. 2017; Ye et } \\
\text { al. 2013; Kaloxylos et al. } \\
\text { 2012; Barmpounakis et al. } \\
\text { 2015; Meola 2016) }\end{array}$ \\
\hline
\end{tabular}




\begin{tabular}{|c|c|c|}
\hline $\begin{array}{l}\text { Autonomous } \\
\text { farming robots }\end{array}$ & $\begin{array}{l}\text { - To obtain detailed maps of the } \\
\text { geographical conditions, topographical } \\
\text { aspects and resources of the area. } \\
\text { - To handle essential agricultural tasks such } \\
\text { as harvesting crops at a higher volume and } \\
\text { faster pace. } \\
\text { - To allow for more acreage to be working } \\
\text { for more extended periods. } \\
\text { - To better manage irrigation systems with a } \\
\text { significant impact on the 'world's water } \\
\text { supply. }\end{array}$ & $\begin{array}{l}\text { (Fountas et al. 2015; } \\
\text { Wolfert et al. 2017; } \\
\text { Floreano and Wood 2015; } \\
\text { Zhao et al. 2016; Emmi et } \\
\text { al. 2014; Pedersen et al. } \\
\text { 2006; Yaghoubi et al. } \\
\text { 2013; Meola 2016) }\end{array}$ \\
\hline $\begin{array}{l}\text { Blockchain in } \\
\text { AgriFood supply } \\
\text { chains }\end{array}$ & $\begin{array}{l}\text { To improve traceability and help with } \\
\text { prevention of food fraud, false labelling } \\
\text { and tracing back to the source of origin. }\end{array}$ & $\begin{array}{l}\text { (Ge et al., 2017; Casado- } \\
\text { Vara, et al., 2018) }\end{array}$ \\
\hline $\begin{array}{l}\text { Smart devices for } \\
\text { the farmers }\end{array}$ & $\begin{array}{l}\text { To remotely monitor the yield, crops, } \\
\text { machinery and livestock, as well as obtain } \\
\text { stats on the livestock feeding and produce. }\end{array}$ & $\begin{array}{l}\text { (Wolfert et al. 2017; } \\
\text { Popović et al. 2017; } \\
\text { Barmpounakis et al. 2015; } \\
\text { Kaloxylos et al. 2012) }\end{array}$ \\
\hline $\begin{array}{l}\text { Drones over the } \\
\text { farming lands }\end{array}$ & $\begin{array}{l}\text { - To render maps processing spatial data, and } \\
\text { applying analytical methods to geographic } \\
\text { datasets, including the use of geographic } \\
\text { information systems (GIS) } \\
\text { - To survey the farming land and generate } \\
\text { crop data, run precise statistical predictions } \\
\text { for the crops and livestock. } \\
\text { - To help in mapping the fields, monitor crop } \\
\text { canopy remotely and check for anomalies. }\end{array}$ & $\begin{array}{l}\text { (Yahya 2018; Meola 2016; } \\
\text { Floreano and Wood 2015; } \\
\text { Huuskonen and Oksanen } \\
\text { 2018; Moskvitch 2016; } \\
\text { Unal and Topakci 2015) }\end{array}$ \\
\hline $\begin{array}{l}\text { Vertical farming } \\
\text { innovations }\end{array}$ & $\begin{array}{l}\text { Hydra, aqua and aeroponic technology to } \\
\text { grow more crops in less space, without the } \\
\text { use of sun or soil; and producing } \\
\text { predictable results of the harvest, less } \\
\text { impact on the environment, faster } \\
\text { harvesting period and superior quality of } \\
\text { food. }\end{array}$ & $\begin{array}{l}\text { (Yahya 2018; Lu and } \\
\text { Grundy 2017; Al-Chalabi } \\
\text { 2015; Banerjee and } \\
\text { Adenaeuer 2014; Pinstrup- } \\
\text { Andersen 2018; Benke } \\
\text { and Tomkins 2017) }\end{array}$ \\
\hline
\end{tabular}


From the applications of Table 2, the specific focus of this study is on the category of the AgriTech drones applying AI techniques for precision agriculture while collecting and acquiring data for targeted decision-making. Drones and robotics for the farming monitor in real-time the growth of the crop, while they inspect the farming fields for multiple agricultural risks (e.g. diseases, humidity, weather conditions.). Drone farming operations boost the production efficiency in sustainable ways, following data-intensive decisions for the AgriFood operations. The study presented here proposes an extension to the use of farming drones, showing that the collective intelligence of swarms could enhance the practices of agricultural drones and robotics. In this study, a form of AI, referred to as Swarm Intelligence, is proposed in order to address defined AgriFood challenges through formal methods. Swarm Intelligence of drones, as a technique is applied recently for multiple military operations and could be extended in various settings (e.g. Cullen et al., 2018). Swarm intelligence of drones could improve the efficiency of AgriFood practices monitored by drones while they carry the already set tasks following unmanned collective behaviour, where human interaction is limited and is applied in a remote basis (limited human supervision).

\section{Research Method}

Following the initial aim and objectives, the study is structured using the design artefact based on AI principles through an empirical example from the agricultural context. The research method of Design Science is deemed most appropriate to understand better how operations can be structured so as to contribute to the design of systems (O'Keefe 2014). Therefore, the study proposes the conceptual design (i.e. the artefact) as a template for AgriFood operations based on AI-oriented applications (inspired by previous military examples of swarm intelligence applications). Design science studies, as those, e.g. Wagner and Thakur-Weigold (2018) or Irani et al. (2018) motivated by the knowledge generation process, follow a knowledge production mode through artefacts. The artefact aims at solving complex and relevant field problems to generate impactful intervention-outcomes (van Aken 2005; van Aken, Chandrasekaran, and Halman 2016). Also, the focus of DSR approaches is the presented artefact which aims for relevance to practice, and therefore the target is the impact and not solely knowledge generation (van Aken 2005; Holmström, Ketokivi, and Hameri 2009). To bridge the gap between theory and impact, DSR is motivated by problem-solving practices but also has a scope within theory enhancement which can complement one another (Holmström, Ketokivi \& Hameri, 2009). 
For Design Science Research (DSR) paradigm, the artefact poses a representation of how the proposed solution to a specific problem could be enacted in practice (O'Keefe 2014; Hevner and Chatterjee 2010; Hevner et al. 2004). For the AgriFood Operations, the specific problem arises, when the arable land is not easily accessible, and innovative solutions should be proposed for remote operations of everyday farm tasks. The DSR approach focuses on specific problems (i.e. in AgriFood production) which inform the defined example scenario while ensuring that all aspects of the problem will be captured. The DSR approach proposed in this study will examine a variety of aspects and propose solutions for instances of small farms. The objectives that represent a solution will also be articulated (O'Keefe 2016; O'Keefe 2014) in the form of evaluation of the example scenario.

The integration of the AgriFood Sustainability challenges and AI underpins this study theoretically. The AgriTech background will assist in exploring the proposed approach of 'swarm 'intelligence' as an artefact developed through a Design Science around the food security goal. The artefact provides a technique within the significant and under-researched topic and encourages the academic and practitioner communities to pursue further research towards novel AI applications. The research strategy followed for this study is similar to previous studies describing AgriFood problems (e.g. Irani \& Sharif, 2018) adapting the design science principles as presented by O'Keefe (2014) but also informed by the previous background of DSR (Hevner and Chatterjee 2010; Gregor and Hevner 2011; Hevner et al. 2004; Peffers et al. 2008). Hereafter, the research design is illustrated in Table 3.

Table 3: Research Design of the study based on O'Keefe (2014).

\begin{tabular}{|l|ll|}
\hline Activity & Sub-activity \\
\hline Problem & $\begin{array}{l}\text { - Identification of the challenges in AgriFood production } \\
\text { Identification }\end{array}$ & $\begin{array}{l}\text { Understand the current operations for AgriFood production (define } \\
\text { what AgriTech solutions are available in the farming field) }\end{array}$ \\
\hline Objectives of & $\begin{array}{l}\text { - Define the problem setting } \\
\text { Solution }\end{array}$ & $\begin{array}{l}\text { (application of swarm intelligence for drones) } \\
\text { - }\end{array}$ \\
\hline
\end{tabular}




\begin{tabular}{|c|c|}
\hline Development & $\begin{array}{l}\text { - Present the artefact design through the defined problem } \\
\text { - Apply argumentation and abductive reasoning for swarm operation } \\
\text { and decisions } \\
\text { - Assignment of policies for the drones and conflict resolution } \\
\text { - Presentation of the case example and example of decisions for the } \\
\text { swarm }\end{array}$ \\
\hline $\begin{array}{l}\text { Testing and } \\
\text { Demonstration }\end{array}$ & $\begin{array}{l}\text { - Test run of commands for the swarm task list } \\
\text { - Representation of the use of the design through an example }\end{array}$ \\
\hline Evaluation & $\begin{array}{l}\text { - Discuss the impact of the AgriFood sector } \\
\text { - Identify links and implications for food security and the SDGs }\end{array}$ \\
\hline
\end{tabular}

\section{Swarm Intelligence of AgriTech drones: the DSR artefact}

The Swarm Intelligence techniques for AgriTech drones will be developed here; through a DSR approach (Gregor and Hevner 2011; Hevner and Chatterjee 2010; Hevner et al. 2004; Peffers et al. 2007). The artefact is a technique, based on formal methods (i.e. argumentation and abductive reasoning) for developing new ways of acquiring data from the farming field, farming management based on AI-enabled operations, and overall unmanned monitoring of farming practices for inaccessible farming land. The conceptual structure of the artefact presents how the technique can be applied in AgriFood operations of small farms. The conceptual structure is based on initial exploratory research of the agricultural context and follows qualitative evaluation methodologies to refine and examine its utility, reliability and content validity. A scenario (Wright and Cairns 2011; Cairns, Goodwin, and Wright 2016) presents an example of the proposed techniques of swarm intelligence to show the applicability of the approach in the agricultural context. The abduction supports the decision-making processes when the swarm intelligence is applied to the specific context of AgriFood operations and processes.

Artificial Intelligence (AI) by principle focuses on cognitive processes and reasoning (Pomerol 1997; Bawack, Wamba, and Carillo 2019), and the decisions related to human intelligence which are represented by computational and formal methods (Bielli and Reverberi 1996). Therefore, the DSR is based on scenarios in an abductive form, to represent the associated decisions related to the defined problem of the farming sector and the behaviour of the actors is likely to have a direct influence on the future implications of the particular problem area and 
the alternative strategic decisions. The directions, decisions and conflicts in the scenario will be addressed through the use of a semi-natural policy language and abductive reasoning techniques (Kakas and Moraitis 2003; Karafili and Lupu 2017; Karafili, Spanaki, and Lupu 2018).

\subsection{Problem Identification}

One of the multiple challenges of the AgriFood sector the last decades could be related to the limited farming land and scarcity of natural resources (FAO, 2018). The increasing requirement of more extensive farming land, less waste of the natural resources and agrarian production indicate that there should be precise AgriFood operating models supported by data-driven decisions (Pham and Stack 2018; Karim, Karim, and Frihida 2017). While the arable land is limited; innovative applications of AI and AgriTech could develop ways to farm inaccessible areas (Unal and Topakci 2015). AgriTech drones could assist precision agriculture by collecting data from the fields, and support monitored human decision making for everyday tasks (e.g. disease inspection, crop monitoring ) and AgriFood operations (e.g. irrigation, fertilisation etc.) of the farm. However, with the view to achieving food security goals, human intelligence should be supported by unmanned devices based on AI that assists for decision-making and operations of dispersing farming land as well. Therefore, the identified problem this study focuses on is reversing inaccessible areas to arable farming land with the support of AI applications.

AI provides multiple applications of AgriTech drone technology for precision farming while an extension of this with swarms of drones that could facilitate and perform tasks monitored from a distance or even in an unmanned way. Swarm Intelligence could support decision-making but also the everyday farming operations of inaccessible land. Specifically, this land is remote and inaccessible for casual human involvement in farming operations; it is a situational challenge due to various limitations (e.g. geographical, morphological.) which make the arable land idle. Applications of Swarm Intelligence could facilitate remote monitoring, precision farming and operations in areas where AgriFood production was not possible before in conventional cases. Enhancing the performance of inaccessible farms could improve the yields and the overall efficiency and production of these areas. 


\subsection{The proposed solution: Swarm Intelligence for AgriFood Operations}

The section here presents briefly an indicative scenario where a swarm of drones is used for farming operations. In particular, a swarm, denoted with $S$, composed of 5 drones, $\mathrm{D}_{1}, \mathrm{D}_{2}, \ldots$, $\mathrm{D}_{5}$, is used by a farmer, $F$, to collect data and supervise one small disperse farm. In particular, this farm is located in a remote area, and it is difficult to be accessed. The swarm of drones has a pre-established path to follow in order to reach the farm. The farm is located in an area with inadequate network coverage, and the drones are not able to communicate directly with the farmer, but only between them and therefore applications of decision-making should be supported often without human supervision.

Figure 1: Scenario presenting a swarm of drones.

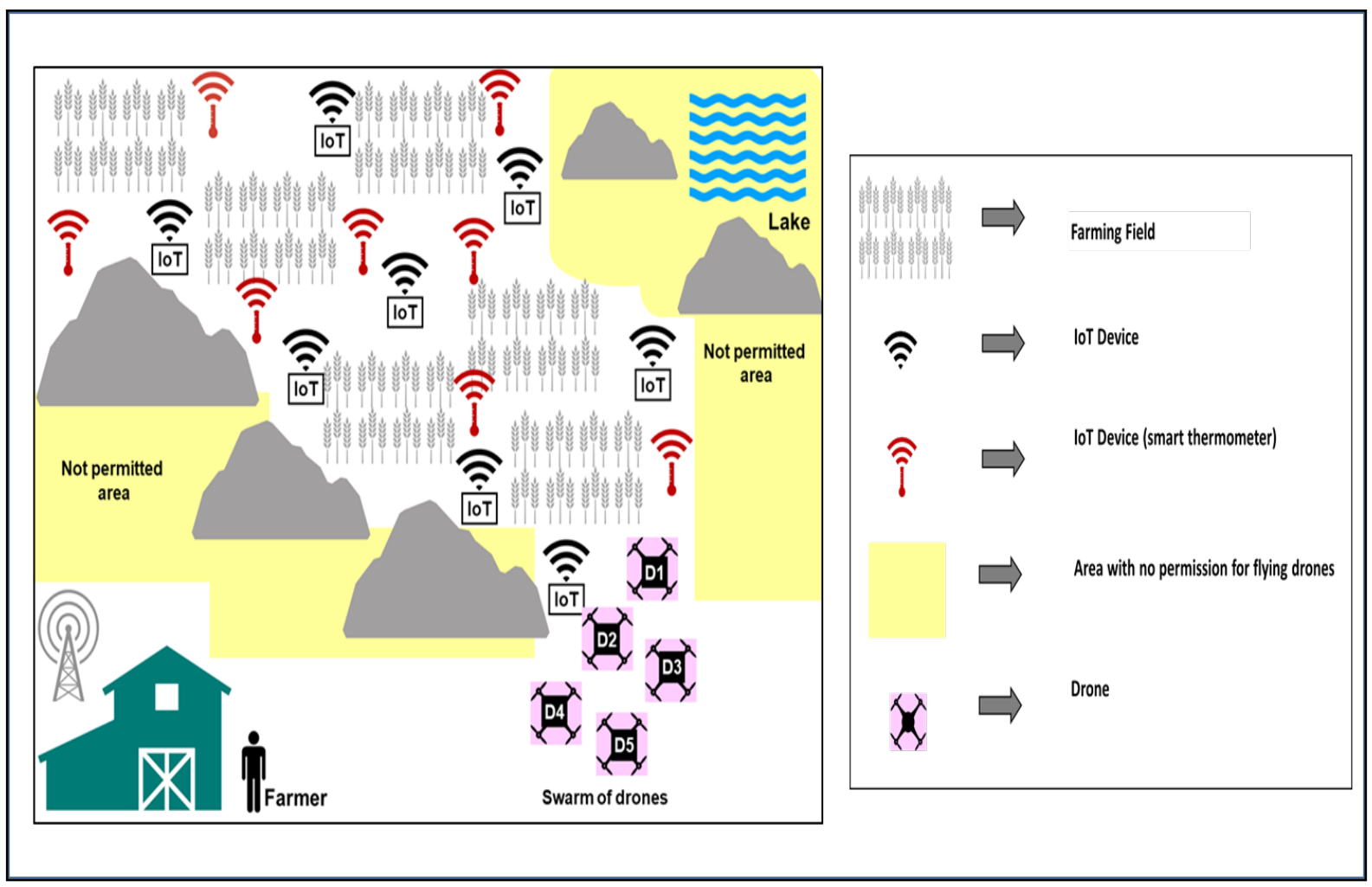

The farmer equips the drones with the essential information about the areas where they need to fly or land, and the areas where they are forbidden to fly/land, in Figure 1 these areas are represented in yellow. The drones are set with a list of tasks to be performed, e.g., collect data from the farm, fertilise, water, or plant seeds. The drones also collect visual data, e.g., pictures of the farming area, and data about the soil, e.g., humidity. Data collection also includes soil information by connecting with the IoT devices that are located on the ground. The level of fertilisation and watering will strictly depend on the gathered data. 
The example is presenting how a swarm of AgriTech (policy-enabled) drones could operate by exchanging messages between each other and collecting data from the IoT devices installed on the remote farm. The design is intended for research purposes to show an example of specific operations and is not intended for all possible AgriFood operations. For the design, there are some initial assumptions:

- The operator (farmer) defines the lead drone and the emergency drone (they can be different drones or the same) in advance, and there is a decentralised operation once the drones leave the base of the farmer.

- The drones of the swarm can autonomously react to certain situations when there is a technical problem of the lead drone, or the collected data indicate an alternative/ emergency action.

- The communication between a drone and another drone of the swarm is vital. Appropriate communication is key for the coordination of the operations performed. Sharing data between the drones can facilitate the exchange of information for precise agrarian operations performed in the remote field.

- There is an acknowledgement of all the messages included in the scenario which is received successfully.

In Figure 2, the message sequence diagram is presented, corresponding to the scenario above. In detail, the operation commences at time T1 (times are shown to the left of the diagram) when the farmer sends a FormSwarm message to appoint D3 as the lead drone. Next, at time T2, the leader drone D3 sends the JoinSwarm message to the each of the other drones, D1, D2, D4 and D5, to join the swarm. Once all the drones have joined the swarm, they exchange acknowledgement messages (ack) between each other and send an ack message to the farmer to get informed about the swarm formation. The acknowledge messages about the swarm formation are sent to the farmer at the instance of time T3. After receiving the ack messages, the farmer can proceed with the task allocation. In particular, at the instant of time T4, the farmer sends through a TaskCmd message the tasks to be performed by the swarm to the lead drone, D3. The TaskCmd message includes the areas to be supervised, the tasks to be performed in each area (e.g., flying, collecting data, taking photos) and any particular role. The lead drone (D3) plans the operation and in T5 assigns tasks and areas to each drone using Task+Area allocation messages. Every drone sends to the lead drone D3 and the farmer an ack message about the allocated areas and tasks. These ack messages are sent to inform the farmer about the 
allocation and to permit him, in case the farmer does not like the allocation, to make further adjustments.

Figure 2: Command Sequence of the case scenario.

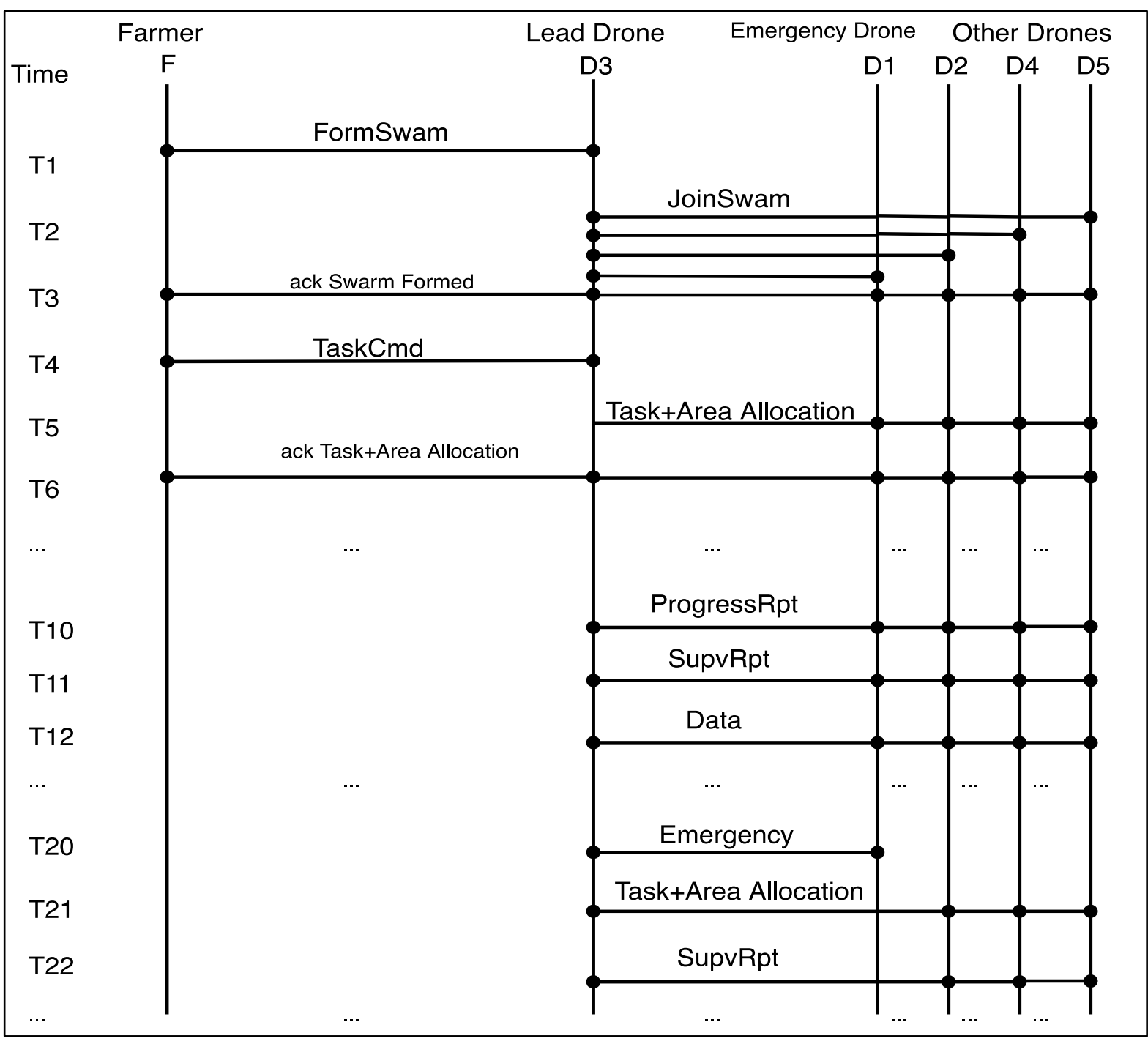

There is an assumption here that after T6, the drones take off and fly to the areas that need to be supervised. During the flight and while performing their tasks, they send to each other messages containing progress report (ProgressRpt), supervision report (SupvRpt) and the collected Data. For the sake of simplicity, this is shown in the form of exchange of these messages between T10-T12.

In an emergency scenario, for example, at the instance of time T20, after exchanging data between each other, the swarm of drones identifies that the humidity of the ground is lower than the average level. Thus, the emergency drone D1 sends the Emergency message to the lead 
drone D3, stating that D1 will fly over non-permitted areas to gather data to identify the cause of the low humidity and will no longer supervise its allocated areas. Lead drone D3 re-plans the mission and sends at the instant of time T21 the new tasks and areas allocation to the remaining drones. The remaining drones (D2-D5) continue to send data, progress report and supervision report to each other. At the end of the mission, all the drones will provide their data and reports to the farmer.

\subsection{Development of the design}

The use of argumentation and abductive reasoning techniques (Kakas and Moraitis 2003; Karafili and Lupu 2017) is presented in various decisions about data processing and sharing practices (Karafili, Spanaki, and Lupu 2018). Argumentation, in this 'study's case, permits the swarm of drones to perform logic-based decision-making (formed in a semi-natural language). In particular, the preconditions for a conclusion to hold are presented below on the right side of the arrow, while the conclusion is on the left side of the arrow. The conclusion represents the taken decision. The conflicting rules are defined as the rules that have opposite conclusions, e.g., rule (a) permits the drone to fly, while rule (b) denies the drone to fly. There may be conflicts in the set of rules when multiple conflicting rules are triggered, e.g., when both rules (a) and (b) can be applied. Argumentation reasoning permits to deal with conflicting rule as it allows to introduce preferences between rules, e.g., rule (a) is preferred over rule (b), denoted by $(a)>(b)$, and in case both rules can be applied, then it is applied only the result of rule (a).

\subsubsection{Coordination of the swarm}

The drones $\left(\mathrm{D}_{\mathrm{i}}\right)$ that are part of the swarm $S$ are permitted to send data to each other and the farmer $F$, represented by rule (1). The drones are permitted to send requests of data (req data) and acknowledgements (ack) of received data to the IoT devices, where it is denoted with $I$ the set of IoT devices in the ground that are trusted, represented by rule (2). The drones are only permitted to send/exchange data between them (deny access to others), represented by rule (3).

$$
\begin{aligned}
& \operatorname{send}\left(D_{i}, X, \text { data, } T, \text { permit }\right) \leftarrow D_{i} \in S,(X \in S \text { or } X=F) \\
& \operatorname{send}\left(D_{i}, X, \text { data, } T, \text { permit }\right) \leftarrow D_{i} \in S, X \in I, \text { data } \in\{\text { req_data, ack }\} \\
& \operatorname{send}\left(D_{i}, X, \text { data, } T, \text { deny }\right) \leftarrow X \notin\{I, S\}, X \neq F
\end{aligned}
$$

From the above rules, (1) and (2) have opposite conclusions concerning rule (3), but they are not triggered at the same time. Thus, this case will not have that rule (1) and (3), or (2) and (3) 
are applied at the same time as the preconditions are specific to each case and are disjunctive between each other. The above rules can support the coordination between the drones and assure that there are no synchronisation problems (in case that data were shared with other devices or parties).

\subsubsection{The leading drone}

There is a predefined decision from the swarm operator (farmer at this instance) about the leader drone, denoted by $\mathrm{D}_{\mathrm{L}}$. The leader drone has a key role in the swarm as it is controlling and synchronising the operations and sends the directions for each drone. In case something happens to the leader drone, then another one gets this role (the sequence of this is also predefined). The role of the leader drone is predetermined, and the main tasks include the allocation of a geographic area to be supervised to each drone, including itself. The directions for the geographical area to be supervised can also be allocated by the farmer; however, there could be cases that the drones can autonomously react to certain situations (e.g. when they have to change lead drone because of some technical problem). The geographical areas to be supervised are allocated only by the leader drone and the farmer, represented by rule (4), nobody else can allocate the areas to be supervised, represented by rule (5).

$$
\begin{aligned}
& \operatorname{send}(A, X, \text { data, } T, \text { permit }) \leftarrow X \in S,\left(A=D_{L} \text { or } A=F\right) \text {, data = allocated_area }(X) \\
& \operatorname{send}(A, X, \text { data, } T, \text { deny }) \leftarrow\left(A \neq D_{L} \text { and } A \neq F\right) \text {, data }=\text { allocated_area }(X)
\end{aligned}
$$

Rule (4) and (5) have opposite conclusions, but they cannot be applied at the same time. The same for rules (4) and (3), they are not triggered on the same time, and rule (5) and (2) do not apply at the same time as the data are of a different type. While rule (5) conflicts with rule (1). In particular, rule (5) is stronger than the rule (1), denoted by (5)>(1). The conflict resolution for the above-predefined rules is represented in Appendix (Figure a).

\subsubsection{Supervision drone tasks for the farm}

The drones need to collect information from the IoT devices located on the ground of the farm. They are allowed to gather information from the IoT devices of the allocated areas to be 
supervised, represented in rule (6). The drones are not allowed to gather information from other entities ${ }^{1}$.

(6) $\quad \operatorname{collect}\left(D_{i}, X\right.$, data, $T$, permit $) \leftarrow D_{i} \in S, X \in I, X \in$ allocated_area $\left(D_{i}\right)$ $\operatorname{collect}\left(\mathrm{D}_{\mathrm{i}}, \mathrm{X}\right.$, data, $\mathrm{T}$, deny $) \leftarrow$

The drones of the swarm are allowed to take pictures in all the areas, except for the areas where they are not permitted to fly.

$$
\begin{aligned}
& \text { photo }\left(D_{i}, \text { area, } T \text {, permit }\right) \leftarrow D_{i} \in S \text {, area } \in \text { Perm_Area } \\
& \text { photo }\left(D_{i} \text {, area, } T \text {, deny }\right) \leftarrow
\end{aligned}
$$

The drones are permitted to fly only in the permitted areas and are not allowed to fly in other areas.

(10) fly $\left(D_{i}\right.$, area, $T$, permit $) \leftarrow D_{i} \in S$, area $\in$ Perm_Area

(11) fly $\left(\mathrm{D}_{\mathrm{i}}\right.$, area, $\mathrm{T}$, deny $) \leftarrow$

For the above rules, there is a conflict that should be resolved. In particular, rule (6) is in conflict with rule (7), where rule (6) is stronger than rule (7), denoted by (6) $>(7)$; rule (8) is in conflict with rule (9), where rule (8) is stronger than rule (9), denoted by (8)>(9); and rule (10) is in conflict with rule (11), where rule (10) is stronger than rule (11), denoted by (10)>(11). There are specific diagrams in Appendix (Figures b-d) that present the decision-making process for each of the conflicts.

In case the collected data show a low level of humidity of the ground ${ }^{2}$, then a particular drone needs to fly over one of the non-permitted areas and take pictures of the lake that is located nearby. This particular drone that is denoted by $\mathrm{D}_{\mathrm{E}}$, is decided by the farmer and is denoted by $\mathrm{D}_{\mathrm{E}}$. The gathered data is passed to the farmer when the drones return from their mission. The farmer sends the data about the lake and part of the collected data to the local authorities, in

\footnotetext{
${ }^{1}$ This rule is represented by rule (7), which has an empty set of preconditions. This means, that the rule applies always.

${ }^{2}$ The overall humidity level of the ground is calculated and analyzed by the drones, while they exchange the data between each other.
} 
order to, when appropriate, to declare a drought emergency for the area. Below two rules are introduced that represent this exception.

(12) fly $\left(D_{i}\right.$, area, $T$, permit $) \leftarrow D_{i}=D_{E}$, overall(humidity, lower, $T$ ), area $\notin$ Perm_Area

(13) $\operatorname{photo}\left(D_{i}\right.$, area, $T$, permit $) \leftarrow D_{i}=D_{E}$, overall(humidity, lower, $T$ ), area $\notin$ Perm_Area

Rule (12) is an exception to the above rule (11), which denies the drones to fly over a nonpermitted area, and rule (13) is an exception of rule (9), which does not permit to photograph non-permitted areas. Rule (12) is stronger than rule (11) and rule (13) is stronger than rule (9), denoted as (12)> (11) and (13)> (9). The decision-making diagrams are presented, respectively, in Appendix (Figure d and Figure b).

Furthermore, the emergency drone is able to send messages to particular IoT devices that serve as checkpoints in the non-permitted areas, notifying these devices about its emergency mission. This case denotes the set of IoT devices serving as checkpoints with CP.

$$
\begin{aligned}
\operatorname{send}\left(D_{i}, X, \text { data, } T, \text { permit }\right) \leftarrow & D_{i}=D_{E}, \text { data }=\text { emergency, } \\
& \text { overall(humidity, lower, } T), X \in C P, X \notin \text { Perm_Area }
\end{aligned}
$$

The above rule represents an exception and is stronger than the rule (3) that does not allow to send data to other entities, (14)> (3), see Appendix (Figure a). Rule (14) and (5) have opposite conclusions but are not in conflict as they are not triggered at the same time.

\subsection{Test Run}

In the previous sections, an example scenario was provided based on an expressive policy language for performing the specific tasks, solving the various conflicts, and developing the decision- making process for the swarms of drones. More specifically, the below tests were performed to evaluate the proposed solution.

- A conflict resolution analysis through the use of GorgiasB tool. The analysis is performed to test the policies and rules, and it can capture actions that are both permitted and denied at the same instance or even more complicated conflicts. This step was performed through abductive and argumentation reasoning, with the aim to represent the various conflicting rules and priorities, validate and discover the rule preferences 
between them. Gorgias $\mathrm{B}^{3}$ is a tool for preference-based argumentation using a graphical interface.

- A conflict identification analysis (for simple and complex conflicts) and solve them by providing preferences between rules. The use of argumentation reasoning permits us to deal with conflicting rules and to provide preferences. The use of abductive reasoning permits us to deal with missing information, in case, not all the required information are given during the execution.

The proposed solution and associated conflict resolution were examined through an example case of the swarm of drones. The identified conflicts were the correct ones, and their resolution did not derive further conflicts.

\subsection{Demonstration}

In the demonstration of the case example, this study assumes that the drones have already received directions and information about the permitted areas where they can fly and the supervised areas (as explained in 4.2.). The allocated areas are shown as in Figure 3, where each of the drones needs to fly to their allocated areas without passing by the non-permitted areas, represented as the yellow areas.

The drones, after arriving at the allocated areas send requests to the IoT devices for data collection. After the data collection task is completed, they share with other drones the collected data. Given the geographical distance between each other, drones might use other drones as a communication bridge to reach other drones from a distance. The exchange of messages between the drones are permitted as they comply with the rule (1) because the drones are all part of the Swarm of Drones (S).

$$
\operatorname{send}\left(D_{i}, X \text {, data, } T \text {, permit }\right) \leftarrow D_{i} \in S,(X \in S \text { or } X=F)
$$

The data gathered, provide the essential information and support the calculations of the overall humidity level. This calculation is also made by taking into consideration the distance (and geographical location) from where the data are collected. If the overall humidity is lower than

\footnotetext{
${ }^{3}$ For more information on GorgiasB argumentation tool, please visit http://gorgiasb.tuc.gr/
} 
a particular level, then there is an emergency situation, and the swarm of drones should follow a different routine. In particular, in case of an emergency, the designated emergency drone, in this case, D1, is set to fly across the non-permitted area in order to take pictures of the lake to check the conditions. While D1 flies towards the lake, the other drones take over the supervised allocated area for D1 following the designated alternative task list. The leader drone has a role in coordinating the swarm while sending directions to the other drones of the newly allocated areas Figure 4.

Figure 3: Supervised Areas Allocation for the Swarm of Drones

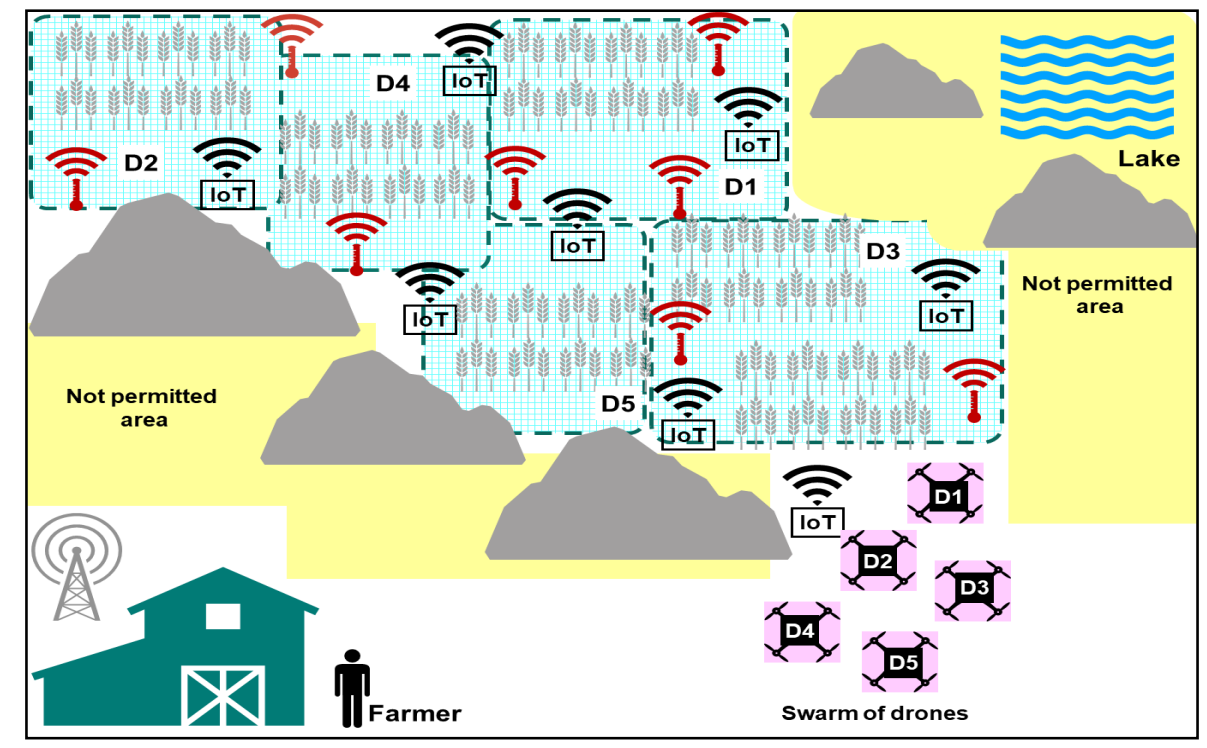

Figure 4: New reallocation of the supervised areas to the remaining Drones

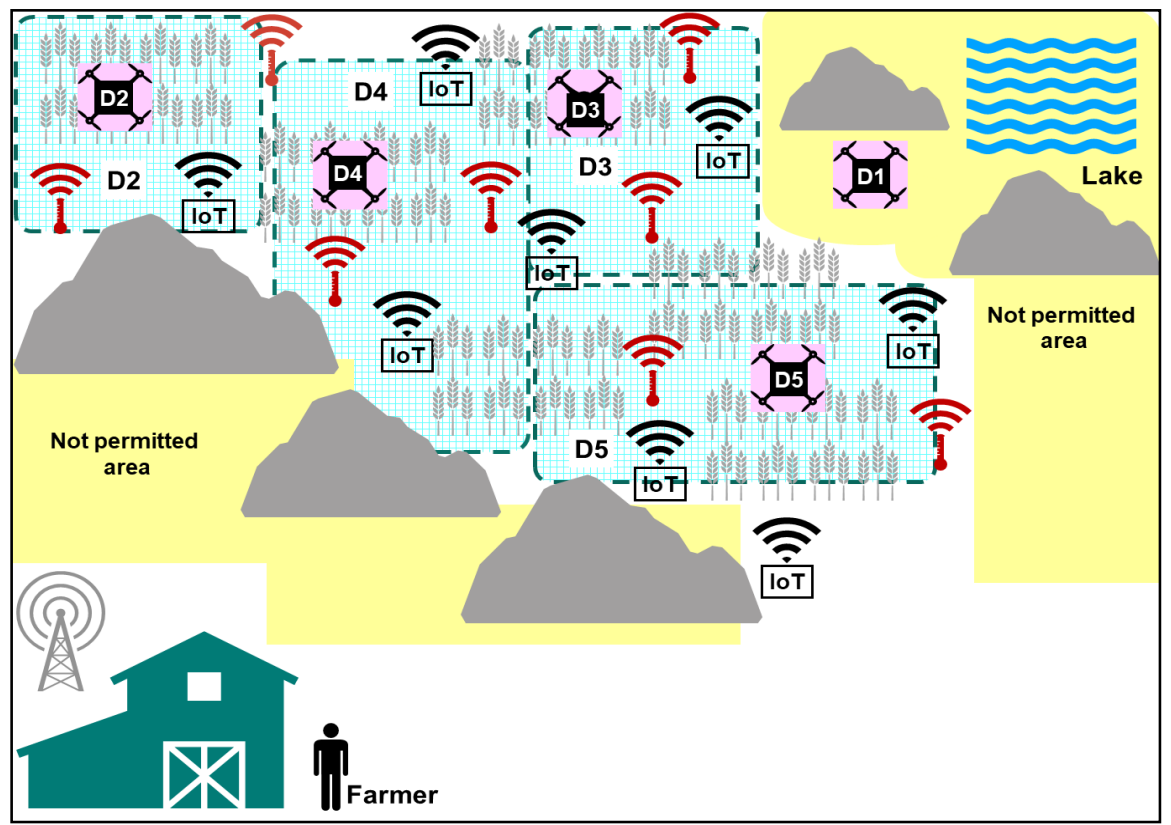


Drone $\mathrm{D}_{1}$ is permitted to fly over the non-permitted areas towards the lake and to take pictures given the new emergency task/mission, as the overall humidity is lower than the threshold, and this is allowed because it is the emergency drone, as represented in rule (12) and (13). The decisions for the demonstration cases is represented in more detail in the decision-making diagram, respectively represented in Appendix (Figure d and Figure b). The decision-making diagrams show the sequence followed for the two decisions and the other rules that could be overruled in emergency situations.

\section{Discussion and links to SDGs}

Inaccessible land cannot be monitored regularly by farmers, and therefore the condition of the crop and yield could not be produced sustainably. Even with AgriTech drones acting in an individual pattern, AgriFood problems of arable land cannot provide a full solution for remote farming land. In such situations, human intelligence should be supported by applications of AI to ensure the sustainability and efficiency of farming remote areas. AI Applications in various AgriFood fields are supported and they are in line with extant literature (Tripicchio et al. 2015) where the use of drone technology for smart farming has been asserted as an effective tool that can provide farmers with a 'bird's eye view of their fields and terrain to provide precision evaluations. Similarly, in this study, the benefit of using drone does seek to allow the farmers to survey the land area efficiently and make better use of farmer time.

The proposed solution of swarm intelligence in this research is inspired by the way natural ecosystems are acting and closely relates to the concept of biomimicry (Kennedy et al. 2015). For example, a swarm of bees or birds could reach areas where farming could not be possible following the traditional patters of AgriFood operations. Inspired by the way nature acts for AgriFood problems through the interventions of swarms of birds or insects, where the land could be transformed to arable through such ways, the study proposes Swarm Intelligence of AgriTech drones, to solve similar problems. Biomimicry in this case, like that followed by Swarm Intelligence, is meant not to create a replica of a natural form, process, or ecosystem (Pathak 2019); it is meant to inspire innovative solutions and derive design principles from natural ecosystems and use those principles as a stimulus for ideation and innovation as highlighted in studies such as Kennedy et al. (2015). Such approaches mimicking the natural ecosystems are emerging and gaining scientific consensus rapidly as asserted by Stojanovic (2019) where it is essential for appropriate use of AgriTech. 
The proposed design in this research provides an indicative scenario of how swarm intelligence can contribute towards tackling food security related issues and in doing so, helping progress SDGs within the context of agriculture. As highlighted by normative literature the critical challenges in agriculture, like soil degradation and diminishing biodiversity, are instigated by unsustainable models of food systems. Therefore, the proposed solution of swarm intelligence helps contribute to the SDG 2 - Zero Hunger as the inaccessibility of arable farming areas issue is resolved, and this is an improvement in the rural agricultural infrastructure. Also, the drones collect data about the farm, fertilisers, water, and the soil and based on these; the farmer can make more informed decisions about the use of resources and land. This case is related to the implementation of resilient and sustainable agriculture practices and is in line with extant studies such as Zhang et al. (2016). Investments in AI and specific to AgriTech drone technology could foster and improve rural agricultural infrastructure (Unal and Topakci 2015). The proposed case in this research supports and contributes to the emerging literature (e.g. Khamis et al., 2019) that highlight AI as an enabler for achieving SDGs. The use of AI to fight hunger through precision farming, image analytics, in-field monitoring of harvest yield data and weed control are ways in which drones and AI and can support sustainable food production. The use of data analytics techniques can help assess the health of crop/soil accurately and predict and prevent diseases with high accuracy with optimal pesticide management and application (Fountas et al. 2015; Backman et al. 2019). In doing so, allowing for improved production and support research and experiments in food safety and related fields of biotechnology. Such tech-driven farming and production techniques positively contribute to addressing SDG 2 to end hunger by achieving food security and improved nutrition and promoting sustainable agriculture.

Through the design approach of this research, agribusiness innovation is encouraged by using AI solutions to solve agricultural problems which are related to SDG 12 - Responsible Consumption and Production. Concerning SDG 12, the proposed swarm intelligence solution not only could enable the reduction of food losses and waste (by applying precision farming practices), but it also encourages agricultural land productivity through the more efficient monitoring of the farming land (unmanned operations of distant land). Increasing agricultural land productivity is a crucial factor highlighted in the literature by authors such as Conceicao et al. (2016) that results in responsible production. In particular, the data that are collected by the drones are key in improving the productivity of the idle land, which in conventional conditions is fertile but is not arable. In this way, the performance of inaccessible farms could 
be significantly improved, and the real needs of the produce are better assessed through technology. This, in turn, results in encouraging agribusiness innovation which helps support the goal of responsible production for agripreneurs as emphasised in findings arising from reports such as Earth Security Group, (2018).

The proposed swarm intelligence design approach also contributes to SDG 15 - Life on Land where some of the key foci of this goal are to protect, restore, and promote the long-term use of terrestrial ecosystems, prevent desertification for example through inappropriate agriculture and halt and reverse the degradation of land and biodiversity loss. The drone-based case proposed in this research seeks to help farmers reach the inaccessible areas of agricultural land that would not be possible to be farmed if the AgriTech did not provide such applications of drones and robotics. Hence, it could be posited that drones support in exploring and restoring the inaccessible farming area where possible. Besides, the use of the drone collected data, and AI-driven predictive analytics in this context can help monitor life on land such as farming land-use changes, food security and nutrition, weather-related stresses and disease outbreaks in the crops. Thus, this research contributes to existing knowledge around AgriTech use by framers for smart prevention, better preparedness and effective responses to tackle life on land issues aligned to SDG 15.

The Swarm Intelligence artefact contributes to progressing the aforementioned SDGs while adopting smart and intelligent farming practices to address targeted food security issues. The presented solution (i.e. artefact) can be used by the various AgriFood system stakeholders, i.e. Researchers, industry practitioners, policymakers and consumers in order to preserve its sustainability and tackle global societal challenges, in this case, being food security.

\section{$7 \quad$ Implications of the study}

Despite the challenges of smart farming and the applications of AgriTech can bring about, this research provides several significant contributions to theory and practice that advances the field of smart agriculture and how it seeks to tackle food security and contribute towards the SDGs.

\subsection{Implications for theory}

The Swarm Intelligence solution presents various opportunities implied by the context and applications of AI. AI in the AgriFood sector often appears as machine learning techniques, Big Data analytics tools, as well as an extensive list of other forms including collective swarm 
intelligence of drones or robotics, is a broad area which warrants further exploration. The study extends the context of AgriTech drones, and presents how AI applied in swarms could assist in SDG goals with a particular focus on goals 2 (zero hunger), 12 (responsible production and consumption) and 15 (life on land) - all of which contributes to addressing global food security issues. The study contributes to existing knowledge around SDGs in terms of its implication on the biosphere, society and the economy. More specifically, the proposed AgriTech case in this paper highlights how drone technology can address the protection of the natural ecosystem, which is an essential precondition for sustainable economic development. The scenario posits the artefact and presents a solution to address the problem of idle land in vital areas that could be transformed into arable and sustainably support AgriFood production. Theoretically, to support the arguments as mentioned above, the study is based on and contributes to three key literature streams; the sustainable AgriFood production (Irani and Sharif 2018; Irani and Sharif 2016), food waste elimination (Irani et al. 2018; Despoudi et al. 2018), as well as data-intensive practices and applications in contextual environments (Sivarajah et al. 2017; Karafili, Spanaki, and Lupu 2018). The combination of the background around AgriFood production and the relevant context, the sustainability challenges, and the evolution of data-intensive practices and AI applications could frame and support further the research for most of the challenges around food security and environmental sustainability.

\subsection{Implications for practice}

The study could motivate alternative thinking of a new generation of farmers, large companies in the domain of food production, innovative start-ups, hi-tech professionals and techenthusiasts showing a keen interest in the AgriFood domain in order to increase sustainable food production and lower food prices (Nukala et al. 2016; Meola 2016). Smart Farming and the evolution of digital farming has started having a strong presence in developing countries but also is gradually making the application of data science, sensors, and technology a big part of the AgriFood sector (Braun, Colangelo, and Steckel 2018) and the associated processes to tackle issues such as food security (Brewster et al. 2017). Smart Agriculture enables business models adapted for IoT ecosystems and creates new cooperation opportunities even for smallscale farms, in order to increase productivity by acquiring lower production costs and improving yield quality and quantity. This research highlights that there are also opportunities for monitoring and controlling the entire lifecycle of food production, for traceability purposes and process awareness for the consumers, while enhancing food security and safety. From an 
environmental point of view, smart farms such as the proposed case in this paper can minimise the ecological footprint and environmental impact of the AgriFood practice, and adapt crop management to requirements of climate change, as well as reduce the use of water and other natural resources, and improve soil quality. Precision farming will take agriculture from an industrial-age industry into a digital-age sector. Farmers rather than spending all of their time with their hands in the dirt will be likely to spend also the time in the office and look more like an information technology company, analysing data sets and developing algorithms to improve efficiency (disruptive potential of precision smart farming).

\section{Limitations and the way forward}

Apart from the various opportunities that data-driven AgriFood practices, smart farming and the applications of AI can bring about, it can also introduce considerable challenges, both for the farm and the technical infrastructure that the farming sector encompasses (Brewster et al. 2017). Smart Farming but also in general terms the food systems are comprised of multiple actors, and there is the heterogeneity of different types of actors which means there is no one 'solution that fits 'all' the cases, as there is a diverse range of technological, business model, or regulatory needs of the heterogeneous farming contexts.

AI for AgriFood production appears as a solution for the call of UN SDGs, but also to multiple challenges the AgriFood sector is facing; however, there are also numerous challenges associated with the adoption of the AI paradigm. While focusing on the economics of digital farming, there are multiple constraints regarding farm size and capital investment costs (Lehmann, Reiche, and Schiefer 2012; Brewster et al. 2017). There is a broader tendency of capital-intensive farms to the uptake of IoT technology, and also follow the previous investments in new equipment and machinery, to smart devices (e.g., smart tractors and farming equipment).

Nonetheless, the challenge for small-scale farms comes when they have to share their data (which involves fears of data misuse or losing their competitive advantage). Therefore, the vendors try to make IoT offerings sufficiently attractive. Persuading small farmers to follow a leap forward for their farms, could be mostly facilitated through trial-mode funded programmes or the other financing options available. However, there are still concerns about data sharing as through the funded plans; small farms have to access a supply chain network of smart farms (via, i.e. FIWARE platforms and similar) and share details and information through multiple 
AgriTech applications available for the network (Brewster et al. 2017; Meola 2016; Popović et al. 2017).

While considering the applications of AI, there is also a need to explore the appropriate business models with the requisite privacy settings and control over data and confidentiality levels (Brewster et al. 2017). By ensuring data privacy, ownership, and provenance could allow farms and other AgriFood actors to monetise the data they are producing rigorously (Vaidya, Ambad, and Bhosle 2018; Fountas et al. 2015). The farms should also acquire the education and training aspects necessary to understand how they share their data but also how to utilise AgriTech applications in an optimum manner. Ultimately, there are significant issues around AgriTech applications and the technological underpinnings of Smart Farming according to previous studies (Lehmann, Reiche, and Schiefer 2012; V. Stojanovic et al. 2017; Brewster et al. 2017) and span in a variety of areas. The challenges, according to Brewster et al. (2017), comprise various technological and data management perspectives of AgriTech applications.

The limitations of the study should also be summarised here, as both sector-specific and technological challenges were identified associated with the agricultural context. AI for AgriFood production context can undoubtedly give farmers the best chance of feeding 'society's growing population and tackle food security; there are still some concerns where future research should focus. The study examined an example of a small farm; however, there are new areas to be explored for future studies, in fields such as:

- Insight of the new operational models of the AgriFood sector, where AgriTech is applied.

- Alternative biomimetic ways for the AgriFood sector, using AI for tasks performed currently by human interventions.

- The challenges in implementing AI in farming operations and specifically to the agricultural field, which can yield a strong opposition wave from farmers.

- The availability and use of AgriTech in multiple contexts, but also the data-sharing concerns.

- $\mathrm{AI}$ and AgriFood practices in terms of sustainability and the ethical and practical concerns associated with it.

Food security can be a challenge to be addressed through various applications of AI for the AgriFood sector; however, some key areas should be defined before the implementation of such 
solutions to the farming field. A major concern around the applications of AI and AgriTech comes around the data artefact. This concern appears when the data sharing context is insufficiently defined for heterogeneous data but also the path to better data quality, along with new frameworks to describe and track data processing in different industries. Except for data quality, data privacy is an emerging challenge, as often serious threats arise primarily in the use of IoT and smart devices; along with trust and shared responsibility among the actors and entities involved. Data generation and exploitation strategies can also focus on the organisational aspects as well as the capabilities and skills acquired for building innovation in data-intensive contexts. Ultimately, there is a need for government and training providers also to offer relevant and future proof training for farmers to upskill themselves and be resilient to change with a focus of responsible production and innovative farm management practices.

\section{Conclusions}

Food Security is a major concern for the sustainability of AgriFood production coupled with limited natural resources and arable land. Innovative ways for AgriFood production and sustainability should be introduced, and that was also presented by the UN SDGs, setting priorities and the way forward to think more for solutions for food security through AI applications. Smart AgriFood operations, applying AI techniques through the use of AgriTech (sensors, drones, IoT devices, data analytics platforms etc.) can provide solutions to various problems of AgriFood production, which couldn't be solved with conventional farming approaches and operating models.

The study is problem-oriented and focuses on solution-based approaches to provide indicative techniques for the problem of distant arable land remaining idle. Reversing idle arable land to smart farming fields, through the use of unmanned AgriTech drones, facilitating the farming tasks and operations remotely, could provide an innovative way to extend the AgriFood production as per the call of SDGs. Inspired by nature, through biomimetic examples of bird or insect swarms, the study proposes a Swarm Intelligence artefact, as a solution to the problem of remote arable land.

The authors in this study adopted a DSR approach to present a scenario of swarms of AgriTech drones operating remotely and how farms could be supported daily. The artefact is developed through AI techniques of argumentation and computational logic and provide details on how a swarm of drones could operate and coordinate in various instances. The authors have shown 
that this indicative application of AI for food security problems could set an example of various ways and artefacts that could be developed in order to innovatively transform AgriFood production while supporting the UN goals around sustainability and food security.

The contributions of the study could be considered in three directions. Initially, the background of AgriFood production and the sustainability of ASCs is extended through innovative approaches applying AI and AgriTech to solve various challenges. The challenges of AgriFood sector are vast and unique due to the nature of the sector; therefore, they require solution-based approaches, as the SDGs also highlight it. The solution-based approaches call for DSR in action for AgriFood problems; therefore, the contribution of this study stands also in this direction. Setting the ground for more research in AgriFood sector following DSR paradigm as a research design could present solutions to multiple sustainability issues of the sector, through the design of artefacts. Finally, our study is among the first in the field of food security, to our knowledge, that presents Swarm Intelligence of drones as a solution for AgriFood and farming production (so far similar artefacts were designed for mostly military applications). The authors attempted through the Swarm Intelligence artefact to present in a scenario, biomimetic ways (through AI) of viewing sustainability problems in the way nature could solve them.

\section{References}

Al-Chalabi, Malek. 2015. "Vertical Farming: Skyscraper Sustainability?” Sustainable Cities and Society. doi:10.1016/j.scs.2015.06.003.

Aramyan, Lusine H., Alfons G.J.M.Oude Lansink, Jack G.A.J. Van Der Vorst, and Olaf Van Kooten. 2007. "Performance Measurement in Agri-Food Supply Chains: A Case Study." Supply Chain Management. doi:10.1108/13598540710759826.

Backman, J., R. Linkolehto, M. Koistinen, J. Nikander, A. Ronkainen, J. Kaivosoja, P. Suomi, and L. Pesonen. 2019. "Cropinfra Research Data Collection Platform for ISO 11783 Compatible and Retrofit Farm Equipment." Computers and Electronics in Agriculture 166. doi:10.1016/j.compag.2019.105008.

Banerjee, Chirantan, and Lucie Adenaeuer. 2014. "Up, Up and Away! The Economics of Vertical Farming.” Journal of Agricultural Studies. doi:10.5296/jas.v2i1.4526.

Barmpounakis, Sokratis, Alexandros Kaloxylos, Aggelos Groumas, Lampros Katsikas, 
Vasileios Sarris, Konstantina Dimtsa, Fabiana Fournier, Eleni Antoniou, Nancy Alonistioti, and Sjaak Wolfert. 2015. "Management and Control Applications in Agriculture Domain via a Future Internet Business-to-Business Platform.” Information Processing in Agriculture. doi:10.1016/j.inpa.2015.04.002.

Bawack, Ransome Epie, Samuel Fosso Wamba, and Kevin Daniel André Carillo. 2019. “Artificial Intelligence in Practice: Implications for Information Systems Research." In 25th Americas Conference on Information Systems, AMCIS 2019.

Benke, Kurt, and Bruce Tomkins. 2017. "Future Food-Production Systems: Vertical Farming and Controlled-Environment Agriculture." Sustainability: Science, Practice, and Policy. doi:10.1080/15487733.2017.1394054.

Bielli, Maurizio, and Pierfrancesco Reverberi. 1996. "New Operations Research and Artificial Intelligence Approaches to Traffic Engineering Problems." European Journal of Operational Research. doi:10.1016/0377-2217(96)00010-0.

Braun, Anja Tatjana, Eduardo Colangelo, and Thilo Steckel. 2018. "Farming in the Era of Industrie 4.0.” In Procedia CIRP. doi:10.1016/j.procir.2018.03.176.

Brewster, Christopher, Ioanna Roussaki, Nikos Kalatzis, Kevin Doolin, and Keith Ellis. 2017. "IoT in Agriculture: Designing a Europe-Wide Large-Scale Pilot." IEEE Communications Magazine. doi:10.1109/MCOM.2017.1600528.

Cairns, George, Paul Goodwin, and George Wright. 2016. “A Decision-Analysis-Based Framework for Analysing Stakeholder Behaviour in Scenario Planning." European Journal of Operational Research. doi:10.1016/j.ejor.2015.07.033.

CEMA - European Agricultural Machinery. 2017. FARMING 4.0: THE FUTURE OF AGRICULTURE? http://www.cema-agri.org/page/farming-40-future-agriculture.

Cullen, Alan, Erisa Karafili, Alan Pilgrim, Chris Williams, and Emil Lupu. 2018. "Policy Support for Autonomous Swarms of Drones." In Lecture Notes in Computer Science (Including Subseries Lecture Notes in Artificial Intelligence and Lecture Notes in Bioinformatics). doi:10.1007/978-3-030-04372-8_6.

Defra. 2020. The Future for Food, Farming and the Environment: Policy Statement. 
https://www.gov.uk/government/publications/the-future-for-food-farming-and-theenvironment-policy-statement-2020.

Despoudi. 2019. "Optimized Food Supply Chains to Reduce Food Losses.” In Saving Food. doi:10.1016/b978-0-12-815357-4.00008-0.

Despoudi, Stella. 2020. "Green Supply Chain." In The Interaction of Food Industry and Environment. doi:10.1016/b978-0-12-816449-5.00002-3.

Despoudi, Stella, Grammatoula Papaioannou, George Saridakis, and Samir Dani. 2018. "Does Collaboration Pay in Agricultural Supply Chain? An Empirical Approach.” International Journal of Production Research. doi:10.1080/00207543.2018.1440654.

Dora, Manoj. 2019. "Collaboration in a Circular Economy: Learning from the Farmers to Reduce Food Waste.” Journal of Enterprise Information Management. doi:10.1108/JEIM02-2019-0062.

Duan, Yanqing, John S. Edwards, and Yogesh K. Dwivedi. 2019. "Artificial Intelligence for Decision Making in the Era of Big Data - Evolution, Challenges and Research Agenda." International Journal of Information Management. doi:10.1016/j.ijinfomgt.2019.01.021.

Dwivedi, Yogesh K., Laurie Hughes, Elvira Ismagilova, Gert Aarts, Crispin Coombs, Tom Crick, Yanqing Duan, et al. 2019. “Artificial Intelligence (AI): Multidisciplinary Perspectives on Emerging Challenges, Opportunities, and Agenda for Research, Practice and Policy." International Journal of Information Management. doi:10.1016/j.ijinfomgt.2019.08.002.

Emmi, Luis, Mariano Gonzalez-de-Soto, Gonzalo Pajares, and Pablo Gonzalez-de-Santos. 2014. "New Trends in Robotics for Agriculture: Integration and Assessment of a Real Fleet of Robots.” The Scientific World Journal. doi:10.1155/2014/404059.

FAO. 2014. Building a Common Vision for Sustainable Food and Agriculture. American Journal of Evaluation. doi:10.1177/109821408300400423.

FAO. 2019. The State of Food and Agriculture 2019. Moving Forward on Food Loss and Waste Reduction. Rome. Licence: CC BY-NC-SA 3.0 IGO. FAO. 2019. The State of Food and Agriculture 2019. Moving Forward on Food Loss and Waste Reduction. Rome. Licence: 
CC BY-NC-SA 3.0 IGO. doi:10.4324/9781315764788.

Floreano, Dario, and Robert J. Wood. 2015. "Science, Technology and the Future of Small Autonomous Drones.” Nature. doi:10.1038/nature14542.

Fountas, S., C. G. Sorensen, Z. Tsiropoulos, C. Cavalaris, V. Liakos, and T. Gemtos. 2015. "Farm Machinery Management Information System." Computers and Electronics in Agriculture. doi:10.1016/j.compag.2014.11.011.

Govindan, Kannan. 2018. "Sustainable Consumption and Production in the Food Supply Chain: A Conceptual Framework." International Journal of Production Economics. doi:10.1016/j.ijpe.2017.03.003.

Gregor, Shirley, and Alan R Hevner. 2011. "Introduction to the Special Issue on Design Science." Information Systems and E-Business Management 9 (1): 1-9.

Hevner, Alan, and Samir Chatterjee. 2010. Design Science Research in Information Systems. Springer.

Hevner, Alan, Salvatore March, Jinsoo Park, and Sudha Ram. 2004. "Design Science in Information Systems Research." MIS Quarterly: Management Information Systems 28 (1): 75-105. doi:10.2307/25148625.

Holmström, Jan, Mikko Ketokivi, and Ari Pekka Hameri. 2009. "Bridging Practice and Theory: A Design Science Approach.” Decision Sciences. doi:10.1111/j.1540-5915.2008.00221.x.

Huuskonen, Janna, and Timo Oksanen. 2018. "Soil Sampling with Drones and Augmented Reality in Precision Agriculture." Computers and Electronics in Agriculture. doi:10.1016/j.compag.2018.08.039.

Iakovou, E., D. Vlachos, Ch Achillas, and F. Anastasiadis. 2014. "Design of Sustainable Supply Chains for the Agrifood Sector: A Holistic Research Framework." Agricultural Engineering International: CIGR Journal. doi:10.1108/01443570610672220.

Irani, Zahir, and Amir M. Sharif. 2016. "Sustainable Food Security Futures: Perspectives on Food Waste and Information across the Food Supply Chain." Journal of Enterprise Information Management. doi:10.1108/JEIM-12-2015-0117. 
Irani, Zahir, and Amir M. Sharif. 2018. "Food Security across the Enterprise: A Puzzle, Problem or Mess for a Circular Economy?" Journal of Enterprise Information Management. doi:10.1108/JEIM-03-2017-0045.

Irani, Zahir, Amir M. Sharif, Habin Lee, Emel Aktas, Zeynep Topaloğlu, Tamara van’t Wout, and Samsul Huda. 2018. "Managing Food Security through Food Waste and Loss: Small Data to Big Data." Computers and Operations Research. doi:10.1016/j.cor.2017.10.007.

Kakas, AC, and P Moraitis. 2003. "Argumentation Based Decision Making for Autonomous Agents." Proceedings of the Second International Joint Conference on Autonomous Agents and Multiagent Systems, 883-890. doi:10.1145/860575.860717.

Kaloxylos, Alexandros, Robert Eigenmann, Frederick Teye, Zoi Politopoulou, Sjaak Wolfert, Claudia Shrank, Markus Dillinger, et al. 2012. "Farm Management Systems and the Future Internet Era." Computers and Electronics in Agriculture. doi:10.1016/j.compag.2012.09.002.

Karafili, Erisa, and Emil C. Lupu. 2017. "Enabling Data Sharing in Contextual Environments." In Proceedings of the 22nd ACM on Symposium on Access Control Models and Technologies - SACMAT '17 Abstracts, 231-238. doi:10.1145/3078861.3078876.

Karafili, Erisa, Konstantina Spanaki, and Emil C. Lupu. 2018. “An Argumentation Reasoning Approach for Data Processing." Computers in Industry. doi:10.1016/j.compind.2017.09.002.

Karim, Foughali, Fathalah Karim, and Ali Frihida. 2017. "Monitoring System Using Web of Things in Precision Agriculture." In Procedia Computer Science. doi:10.1016/j.procs.2017.06.083.

Kennedy, Emily, Daphne Fecheyr-Lippens, Bor Kai Hsiung, Peter H. Niewiarowski, and Matthew Kolodziej. 2015. "Biomimicry: A Path to Sustainable Innovation." Design Issues. doi:10.1162/DESI_a_00339.

Khamis, Alaa, Howard Li, Edson Prestes, and Tamas Haidegger. 2019. "AI: A Key Enabler of Sustainable Development Goals, Part 1 [Industry Activities]." IEEE Robotics and Automation Magazine. doi:10.1109/MRA.2019.2928738. 
Kittipanya-ngam, Pichawadee, and Kim Hua Tan. 2020. "A Framework for Food Supply Chain Digitalization: Lessons from Thailand." Production Planning and Control. doi:10.1080/09537287.2019.1631462.

Krejci, Caroline C., and Benita M. Beamon. 2014. "Environmentally-Conscious Supply Chain Design in Support of Food Security." Operations and Supply Chain Management: An International Journal. doi:10.31387/oscm060034.

Lehmann, Richard J., Robert Reiche, and Gerhard Schiefer. 2012. "Future Internet and the Agri-Food Sector: State-of-the-Art in Literature and Research." Computers and Electronics in Agriculture. doi:10.1016/j.compag.2012.09.005.

Lezoche, Mario, Herve Panetto, Janusz Kacprzyk, Jorge E. Hernandez, and $\mathrm{M}^{\mathrm{a}}$ Mar Eva Alemany Díaz. 2020. "Agri-Food 4.0: A Survey of the Supply Chains and Technologies for the Future Agriculture." Computers in Industry. doi:10.1016/j.compind.2020.103187.

Li, F, A Nucciarelli, S Roden, and G Graham. 2016. "How Smart Cities Transform Operations Models: A New Research Agenda for Operations Management in the Digital Economy." Production Planning and Control 27 (6): 514-528. doi:10.1080/09537287.2016.1147096.

Li, Xiaodong, and Maurice Clerc. 2019. "Swarm Intelligence." In International Series in Operations Research and Management Science, 353-384. doi:10.1007/978-3-319-910864_11.

Liao, Yongxin, Fernando Deschamps, Eduardo de Freitas Rocha Loures, and Luiz Felipe Pierin Ramos. 2017. "Past, Present and Future of Industry 4.0 - a Systematic Literature Review and Research Agenda Proposal." International Journal of Production Research. doi:10.1080/00207543.2017.1308576.

Lu, Chungui, and Steven Grundy. 2017. "Urban Agriculture and Vertical Farming." In Encyclopedia of Sustainable Technologies. doi:10.1016/B978-0-12-409548-9.10184-8.

Lundqvist, Jan, Charlotte De Fraiture, and David Molden. 2008. "Saving Water: From Field to Fork Curbing Losses and Wastage in the Food Chain." SIWI Policy Brief.

Margolin, Victor. 1998. "Design for a Sustainable World." Design Issues. doi: $10.2307 / 1511853$. 
Margolin, Victor. 2007. "Design, the Future and the Human Spirit." Design Issues. doi:10.1162/desi.2007.23.3.4

Meola, Andrew. 2016. "Why IoT, Big Data \&amp; Smart Farming Is the Future of Agriculture - Business Insider Deutschland.” Business Insider.

Moazzam, Muhammad, Pervaiz Akhtar, Elena Garnevska, and Norman E. Marr. 2018. "Measuring Agri-Food Supply Chain Performance and Risk through a New Analytical Framework: A Case Study of New Zealand Dairy." Production Planning and Control. doi:10.1080/09537287.2018.1522847.

Moskvitch, K. 2016. “Take off: Are Drones the Future of Farming?" Engineering \& Technology. doi:10.1049/et.2015.0721.

Nukala, R, K Panduru, A Shields, D Riordan, P Doody, and J Walsh. 2016. "Internet of Things: A Review from 'Farm to Fork."” In . doi:10.1109/ISSC.2016.7528456.

O’Keefe, R. 2014. 'Design Science, the Design of Systems and Operational Research: Back to the Future." Journal of the Operational Research Society. doi:10.1057/jors.2012.175.

O’Keefe, R. 2016. "Experimental Behavioural Research in Operational Research: What We Know and What We Might Come to Know." European Journal of Operational Research. doi:10.1016/j.ejor.2015.09.027.

Oesterreich, T D, and F Teuteberg. 2016. "Understanding the Implications of Digitisation and Automation in the Context of Industry 4.0: A Triangulation Approach and Elements of a Research Agenda for the Construction Industry." Computers in Industry 83: 121-139. doi:10.1016/j.compind.2016.09.006.

Papaioannou, Grammatoula, Anne Marie Mohammed, Stella Despoudi, George Saridakis, and Thanos Papadopoulos. 2020. "The Role of Adverse Economic Environment and Human Capital on Collaboration within Agri-Food Supply Chains." International Journal of Information Management. doi:10.1016/j.ijinfomgt.2020.102077.

Papargyropoulou, Effie, Rodrigo Lozano, Julia K. Steinberger, Nigel Wright, and Zaini Bin Ujang. 2014. "The Food Waste Hierarchy as a Framework for the Management of Food Surplus and Food Waste." Journal of Cleaner Production. 
doi:10.1016/j.jclepro.2014.04.020.

Pathak, Shivi. 2019. "Biomimicry: (Innovation Inspired by Nature)." International Journal of New Technology and Research. doi:10.31871/ijntr.5.6.17.

Pedersen, S. M., S. Fountas, H. Have, and B. S. Blackmore. 2006. "Agricultural Robots System Analysis and Economic Feasibility." Precision Agriculture. doi:10.1007/s11119006-9014-9.

Peffers, Ken, Tuure Tuunanen, Marcus A. Rothenberger, and Samir Chatterjee. 2008. "A Design Science Research Methodology for Information Systems Research.” Journal of Management Information Systems. doi:10.2753/mis0742-1222240302.

Pham, Xuan, and Martin Stack. 2018. "How Data Analytics Is Transforming Agriculture." Business Horizons. doi:10.1016/j.bushor.2017.09.011.

Pinstrup-Andersen, Per. 2018. "Is It Time to Take Vertical Indoor Farming Seriously?” Global Food Security. doi:10.1016/j.gfs.2017.09.002.

Pomerol, Jean Charles. 1997. “Artificial Intelligence and Human Decision Making.” European Journal of Operational Research. doi:10.1016/S0377-2217(96)00378-5.

Popović, Tomo, Nedeljko Latinović, Ana Pešić, Žarko Zečević, Božo Krstajić, and Slobodan Djukanović. 2017. "Architecting an IoT-Enabled Platform for Precision Agriculture and Ecological Monitoring: A Case Study." Computers and Electronics in Agriculture 140: 255-265. doi:10.1016/j.compag.2017.06.008.

Schanes, Karin, Karin Dobernig, and Burcu Gözet. 2018. "Food Waste Matters - A Systematic Review of Household Food Waste Practices and Their Policy Implications.” Journal of Cleaner Production. doi:10.1016/j.jclepro.2018.02.030.

Sivarajah, Uthayasankar, Muhammad Mustafa Kamal, Zahir Irani, and Vishanth Weerakkody. 2017. "Critical Analysis of Big Data Challenges and Analytical Methods." Journal of Business Research 70: 263-286. doi:10.1016/j.jbusres.2016.08.001.

Sony, Michael, and Subhash Naik. 2019. "Critical Factors for the Successful Implementation of Industry 4.0: A Review and Future Research Direction.” Production Planning and Control. doi:10.1080/09537287.2019.1691278. 
Stojanovic, Milutin. 2019. "Biomimicry in Agriculture: Is the Ecological System-Design Model the Future Agricultural Paradigm?" Journal of Agricultural and Environmental Ethics. doi:10.1007/s10806-017-9702-7.

Stojanovic, V., Ruth E. Falconer, J. Isaacs, D. Blackwood, D. Gilmour, D. Kiezebrink, and J. Wilson. 2017. "Streaming and 3D Mapping of AGRI-Data on Mobile Devices." Computers and Electronics in Agriculture. doi:10.1016/j.compag.2017.03.019.

Tripicchio, Paolo, Massimo Satler, Giacomo Dabisias, Emanuele Ruffaldi, and Carlo Alberto Avizzano. 2015. "Towards Smart Farming and Sustainable Agriculture with Drones." In Proceedings - 2015 International Conference on Intelligent Environments, IE 2015. doi:10.1109/IE.2015.29.

Tzounis, Antonis, Nikolaos Katsoulas, Thomas Bartzanas, and Constantinos Kittas. 2017. Internet of Things in Agriculture, Recent Advances and Future Challenges. Biosystems Engineering. Vol. 164. doi:10.1016/j.biosystemseng.2017.09.007.

UN Food and Agriculture Organization. 2009. Global Agriculture towards 2050. http://www.fao.org/fileadmin/templates/wsfs/docs/Issues_papers/HLEF2050_Global_Ag riculture.pdf.

UN Food and Agriculture Organization. 2011. Global Food Losses and Waste. http://www.fao.org/fileadmin/user_upload/ags/publications/GFL_web.pdf.

Unal, Ilker, and Mehmet Topakci. 2015. "A Review on Using Drones for Precision Farming Applications.” International Journal of Advanced Robotic Systems. doi:10.5772/62059.

Vaidya, Saurabh, Prashant Ambad, and Santosh Bhosle. 2018. "Industry 4.0 - A Glimpse.” In Procedia Manufacturing. doi:10.1016/j.promfg.2018.02.034.

van Aken, Joan. 2005. "Management Research as a Design Science: Articulating the Research Products of Mode 2 Knowledge Production in Management." British Journal of Management. doi:10.1111/j.1467-8551.2005.00437.x.

van Aken, Joan, Aravind Chandrasekaran, and Joop Halman. 2016. "Conducting and Publishing Design Science Research: Inaugural Essay of the Design Science Department of the Journal of Operations Management." Journal of Operations Management. 
doi:10.1016/j.jom.2016.06.004.

Vlajic, Jelena V., Radomir Mijailovic, and Mariana Bogdanova. 2018. "Creating Loops with Value Recovery: Empirical Study of Fresh Food Supply Chains.” Production Planning and Control. doi:10.1080/09537287.2018.1449264.

Wagner, Stephan M., and Bublu Thakur-Weigold. 2018. "Supporting Collaboration in Humanitarian Supply Chains-Insights from a Design Science Project." Production Planning and Control. doi:10.1080/09537287.2018.1542175.

Wang, Xiaojun, Dong Li, and Xianliang Shi. 2012. “A Fuzzy Model for Aggregative Food Safety Risk Assessment in Food Supply Chains." Production Planning and Control. doi:10.1080/09537287.2011.561812.

Wolfert, Sjaak, Lan Ge, Cor Verdouw, and Marc Jeroen Bogaardt. 2017. "Big Data in Smart Farming - A Review.” Agricultural Systems. doi:10.1016/j.agsy.2017.01.023.

Wright, George, and George Cairns. 2011. Scenario Thinking: Practical Approaches to the Future. Scenario Thinking: Practical Approaches to the Future. doi:10.1057/9780230306899.

Yaghoubi, Sajjad, Negar Ali Akbarzadeh, Shadi Sadeghi Bazargani, Sama Sadeghi Bazargani, Marjan Bamizan, and Maryam Irani Asl. 2013. "Autonomous Robots for Agricultural Tasks and Farm Assignment and Future Trends in Agro Robots." International Journal of Mechanical and Mechatronics Engineering.

Yahya, Noorhana. 2018. "Agricultural 4.0: Its Implementation toward Future Sustainability." In Green Energy and Technology. doi:10.1007/978-981-10-7578-0_5.

Ye, Jiuyan, Bin Chen, Qingfeng Liu, and Yu Fang. 2013. "A Precision Agriculture Management System Based on Internet of Things and WebGIS." In International Conference on Geoinformatics. doi:10.1109/Geoinformatics.2013.6626173.

Zhao, Yuanshen, Liang Gong, Yixiang Huang, and Chengliang Liu. 2016. "A Review of Key Techniques of Vision-Based Control for Harvesting Robot." Computers and Electronics in Agriculture. doi:10.1016/j.compag.2016.06.022. 


\section{Appendix}

\section{Decision diagrams for the conflict resolution}

The decision diagrams for the swarm of drones are presented here and show the conflict resolution and decision-making practices applied with AI. In particular, when the drones can photograph, send information or fly. Figure a represents the decision-making diagram for the instance when a drone is permitted or denied to send data to another entity.

Figure a: Decision-making diagram for the operation 'send'.

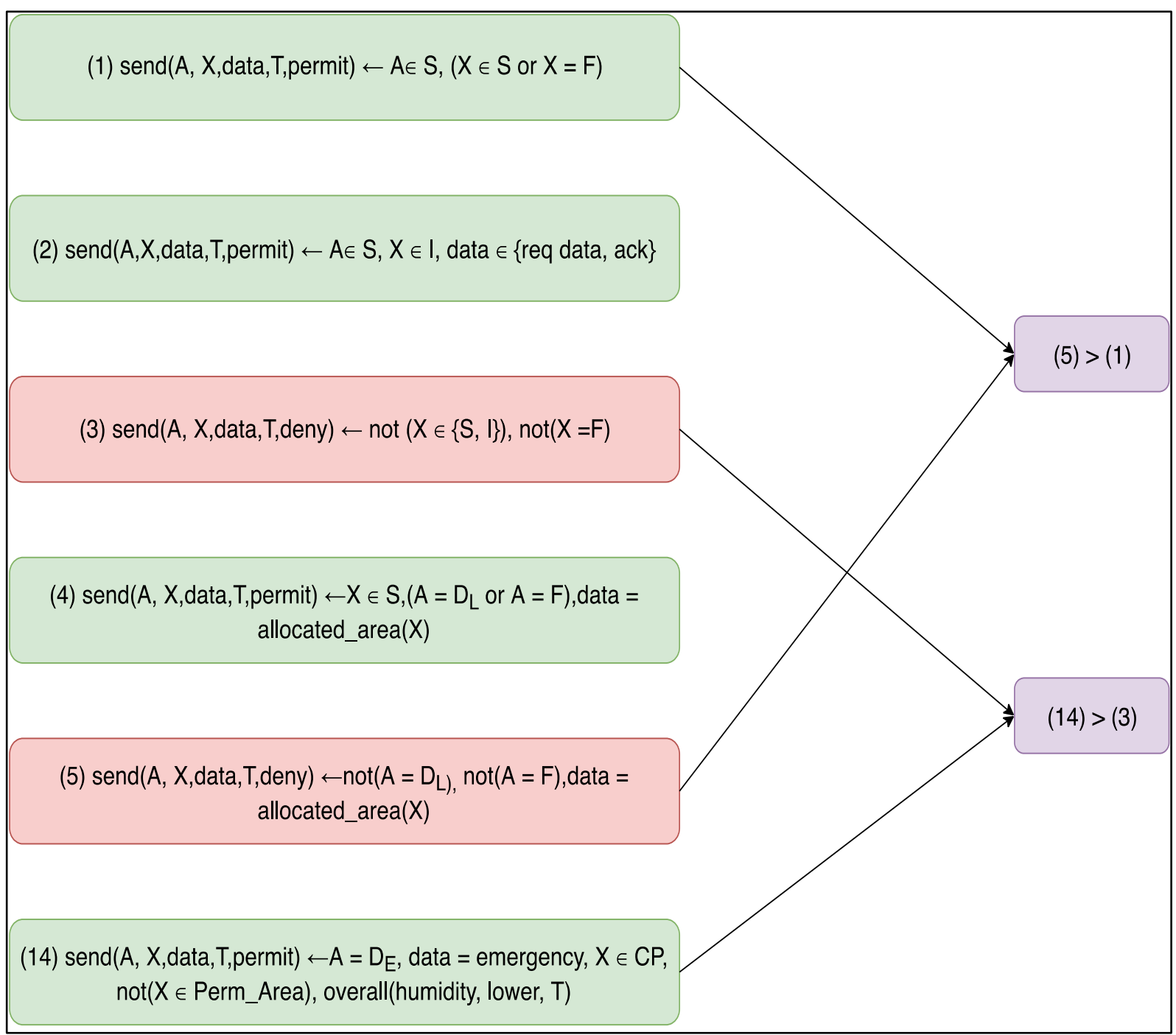

In Figure $b$ there is the decision-making diagram for the instance when the swarm of drones can take pictures, when they can collect data from other devices (in Figure c) and when they are permitted to fly over certain areas (in Figure d). 
Figure b: Decision-making diagram for 'take photos'.

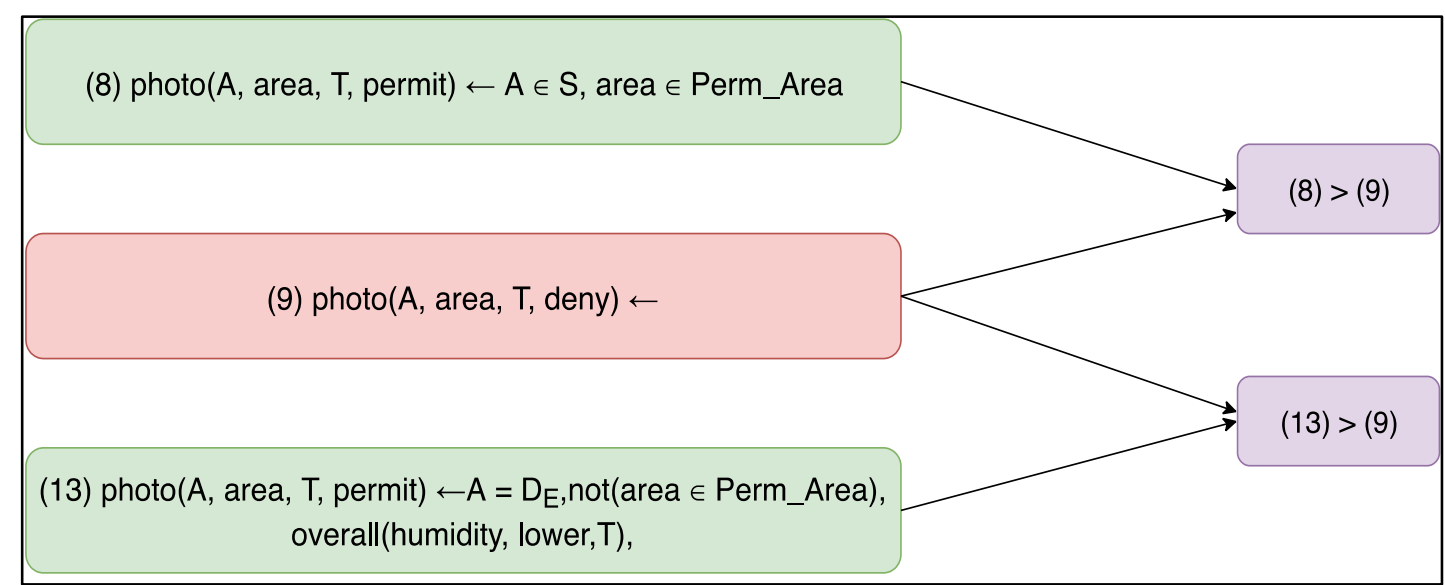

Figure c: Decision-making diagram for the 'collect' action.

(6) $\operatorname{collect}(A, X$, data, $T$, permit $) \leftarrow A \in S, X \in I, X \in$ alloc_area(A)

(7) $\operatorname{collect}(A, X$, data, $T$, deny) $\leftarrow$

Figure d: decision-making diagram for the 'fly' operation.

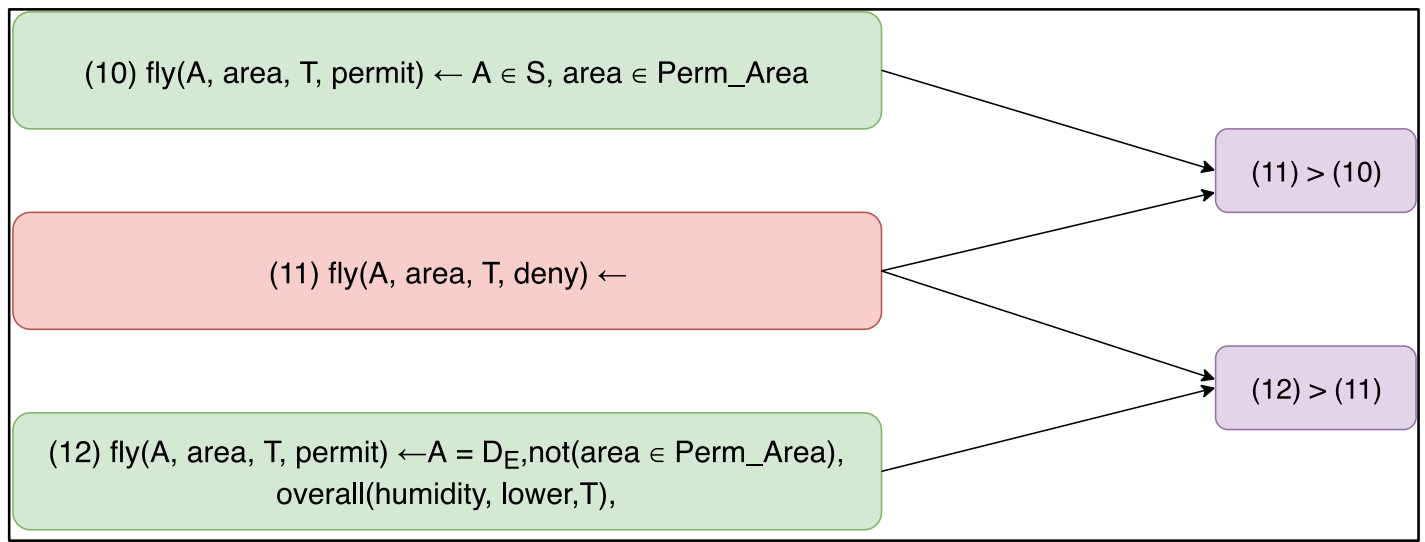

The example presents how the rules and the decision-making process are applied in this particular case study. The Swarm of drones is composed of 5 drones denoted as $\mathrm{D}_{1}, \mathrm{D}_{2}, \mathrm{D}_{3}, \mathrm{D}_{4}$ and $\mathrm{D}_{5}$. The leader drone $\left(\mathrm{D}_{\mathrm{L}}\right)$ is decided by the farmer $(F)$ in this case and is drone $\mathrm{D}_{3}$, while the emergency drone $\left(\mathrm{D}_{\mathrm{E}}\right)$ is drone $\mathrm{D}_{1}$. 